\title{
Impedance-Based Interactions in Grid-Tied Three-Phase Inverters in Renewable Energy Applications
}

\author{
Teuvo Suntio ${ }^{1, *(1)}$, Tuomas Messo ${ }^{1}{ }^{10}$, Matias Berg ${ }^{1}$, Henrik Alenius ${ }^{1}{ }^{(\mathbb{D}}$, Tommi Reinikka ${ }^{1}$, \\ Roni Luhtala ${ }^{2}$ and Kai Zenger ${ }^{3}$ (I) \\ 1 Laboratory of Electrical Engineering, Tampere University, 33720 Tampere, Finland; \\ tuomas.messo@tuni.fi (T.M.); matias.berg@tuni.fi (M.B.); henrik.alenius@tuni.fi (H.A.); \\ tommi.reinikka@tuni.fi (T.R.) \\ 2 Laboratory of Automation and Hydraulics, Tampere University, 33720 Tampere, Finland; roni.luhtala@tuni.fi \\ 3 Department of Electrical Engineering and Automation, Aalto University, 02150 Espoo, Finland; \\ kai.zenger@aalto.fi \\ * Correspondence: teuvo.suntio@tuni.fi; Tel.: +358-400-828-431
}

Received: 12 December 2018; Accepted: 28 January 2019; Published: 31 January 2019

check for updates

\begin{abstract}
Impedance-ratio-based interaction analyses in terms of stability and performance of DC-DC converters is well established. Similar methods are applied to grid-connected three-phase converters as well, but the multivariable nature of the converters and the grid makes these analyses very complex. This paper surveys the state of the interaction analyses in the grid-connected three-phase converters, which are used in renewable-energy applications. The surveys show clearly that the impedance-ratio-based stability assessment are usually performed neglecting the cross-couplings between the impedance elements for reducing the complexity of the analyses. In addition, the interactions, which affect the transient performance, are not treated usually at all due to the missing of the corresponding analytic formulations. This paper introduces the missing formulations as well as explicitly showing that the cross-couplings of the impedance elements have to be taken into account for the stability assessment to be valid. In addition, this paper shows that the most accurate stability information can be obtained by means of the determinant related to the associated multivariable impedance ratio. The theoretical findings are also validated by extensive experimental measurements.
\end{abstract}

Keywords: source and load impedance; transient dynamics; stability; grid synchronization; power electronics; power grid

\section{Introduction}

The negative-incremental-resistor oscillations were observed to take place, in practice, already in the early 1970s when an LC-type input filter was connected at the input terminal of regulated converters as reported in References [1,2]. The development of the dynamic modeling method known as state-space averaging (SSA) in the early 1970s [3-5] enabled the theoretical studies of the origin of the input-filter interactions, which were published in the mid 1970s [6,7] by Middlebrook. He stated later that he applied the extra-element-theorem-based (EET) method [8,9] when developing the input-filter-design rules in References [6,7] for the cascaded input-filter-converter system. According to the EET method, the source or load-system-affected transfer function $G_{\text {org }}^{S / L}(s)$ of the converter can be given by

$$
G_{\text {org }}^{S / L}=\frac{1+Z_{n-1} Y_{n-2}}{1+Z_{d-1} Y_{d-2}} \times G_{\text {org }}
$$


where $G_{o r g}(s)$ denotes the original or unterminated transfer function of the converter, $Z_{n-1} Y_{n-2}$ denotes the impedance-admittance product of the numerator polynomial, and $Z_{\mathrm{d}-1} Y_{\mathrm{d}-2}$ denotes the impedance-admittance product of the denominator polynomial, respectively. The formulation in Equation (1) is very useful, because it defines automatically the correct order of the impedance-like elements in the numerator and denominator impedance-admittance products, to perform the source/load analysis in a correct manner as instructed in References [10-12] and implied in Figure 1. The most crucial factor in the analysis of the cascaded systems is to recognize that the duality must be valid at the interface between the upstream and downstream subsystems. This means that the only valid source-sink pairs are Figure $1 \mathrm{a}, \mathrm{d}$ as well as Figure $1 \mathrm{~b}, \mathrm{c}$, respectively. The cascaded system will not be proper with the other source-sink combinations at the interface between the subsystems because of violating Kirchhoff's laws.

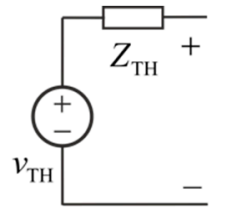

(a)

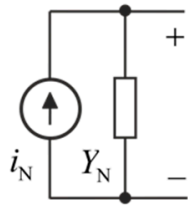

(b)

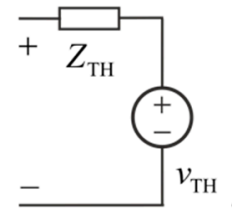

(c)

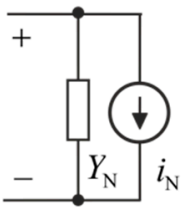

(d)

Figure 1. The source/sink equivalent circuits: (a) Thevenin's source, (b) Norton's source, (c) Thevenin's sink, and (d) Norton's sink.

As Equation (1) indicates, the theoretical formulation in Equation (1) does not contain impedance ratios, but it is sometimes easier to understand the behavior of the impedance-admittance products, when the product is considered as an impedance ratio as in References $[6,7]$. The minor-loop gain launched by Middlebrook in References [6,7] actually denotes the denominator product $Z_{\mathrm{d}-1} Y_{\mathrm{d}-2}$ as minor-loop gain, which can be given equally as $Z_{d-1} / Z_{d-2}$, because $Z_{d-2}=Y_{d-2}^{-1}$. The minor-loop gain actually equals $Z_{\mathrm{TH}} Y_{\mathrm{N}}$ according to Figure 1, which indicates explicitly that the numerator impedance of the impedance ratio (i.e., minor-loop gain) always equals the internal impedance of the voltage-type subsystem, and the denominator impedance equals the internal impedance of the current-type subsystem, respectively [10].

Stability of the cascaded system can be assessed based on $Z_{\mathrm{TH}} Y_{\mathrm{N}}$ by applying Nyquist stability criterion [13], because $\left(1+Z_{\mathrm{TH}} Y_{\mathrm{N}}\right)^{-1}$ forms an impedance-based sensitivity function similarly as $\left(1+L_{\mathrm{X}}\right)^{-1}$ in control engineering [14,15], where $L_{\mathrm{X}}$ denotes the feedback-loop gain. If the phase or gain margin of the feedback loop is low then the sensitivity function will exhibit peaking, which affects the corresponding closed-loop transfer function, and it may cause deterioration in transient response or may make the converter more prone to instability $[14,15]$. The similar phenomena will take place also in case of $\left(1+Z_{\mathrm{TH}} Y_{\mathrm{N}}\right)^{-1}$.

The impedance-admittance product $\left(Z_{n-1} Y_{n-2}\right)$ of the numerator polynomial is not directly related to the system stability similarly as $Z_{\mathrm{TH}} Y_{N}$ is. One of the elements in $Z_{n-1} Y_{n-2}$ equals either $Z_{\mathrm{TH}}$ or $Y_{\mathrm{N}}$ depending on the type of the source/load system (cf. Figure 1), and the other element (i.e., $Z_{n-1}$ or $\left.Y_{n-2}\right)$ is a certain special impedance-like parameter, which will be introduced for the grid-tied three-phase inverters in Section 2. The special parameters of the DC-DC converters are defined in general and given also explicitly for a number of converters in Reference [12]. The impedance-based interactions via the numerator polynomial in Equation (1) may affect the control-related transfer functions or the internal input or output impedances that may deteriorated the transient behavior of the converter as demonstrated in Reference [11].

The input-filter-design rules, introduced in References [6,7], have been later extended to apply for stability and performance assessment in arbitrary systems as well, where the robust stability and performance are defined in the form of forbidden regions out of which the minor-loop gain $\left(Z_{\mathrm{TH}} Y_{\mathrm{N}}\right)$ should stay for the robust stability to exist $[10,16-19]$ as illustrated in Figure 2. The forbidden region induced by the input-filter-design rules $[6,7]$ is assumed to be outside of the circle, which has 
the radius of inverse of the gain margin and the center at the origin (cf. Figure 2, Middlebrook). This forbidden region is deemed to be excessively conservative for general usage, and therefore, reduced forbidden regions are proposed as discussed in Reference [17]. In regard to the input-filter design, Middlebrook's forbidden region is the only possible region for guaranteeing the stability of the cascaded input-filter-converter system (cf. Reference [10]). The smallest forbidden region is proposed in Reference [10] as a circle having the center at the critical point $(-1,0)$ and the radius of inverse of the allowed maximum peaking in the corresponding sensitivity and complementary sensitivity functions as described in detail in Reference [10] (cf. Figure 2, MPC). In principle, the forbidden regions can be applied to the grid-connected three-phase converters and systems as well [20]. The multivariable nature of the grid-tied three-phase converters makes the performance and stability assessment more challenging [20-26], when the inverter-grid stability assessment has to be performed by applying generalized Nyquist stability criterion $[27,28]$ instead of the simple Nyquist stability criterion [13].

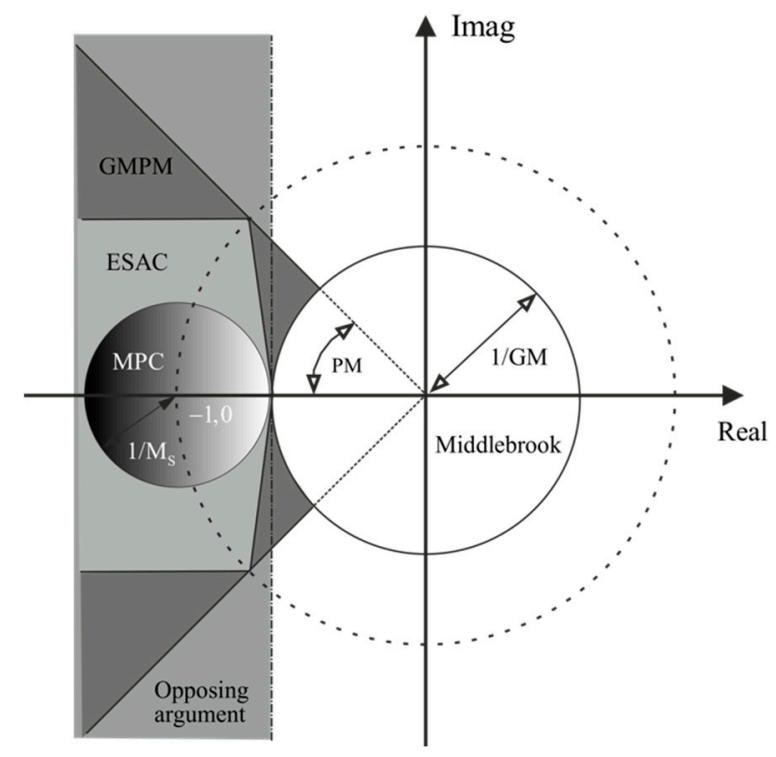

Figure 2. The evolution of forbidden regions according to Reference [11], where GMPM denotes gain and phase margin [16], ESAC Energy Systems Analysis Consortium [17], Opposing argument as the limited real part [18], and MPC maximum peak criteria [11].

The origin of the stability problems in grid-connected systems is usually the negative-incrementalresistor-like behavior at the input or output impedance of the three-phase converter [29-31] similarly as in DC-DC converters discussed in References [1,2]. In three-phase converters, the negative-incrementalresistor-like behavior is either the consequence of the grid synchronization [29-35] or the feedback control from the output-terminal variables [36-43]. In case of grid synchronization, the instability can be mitigated in some extends by lowering the control bandwidth of the phase locked loop (PLL) adaptively when the grid impedance is increasing as discussed in Reference [44]. The grid-connected converters synchronize themselves at the voltage of the connection point known usually as the point of common coupling (PCC). If the grid impedance is low, then the PCC voltage is in phase with the grid voltage. In case of weak grid [45-54], the grid impedance can be rather high, which changes the phase of the PCC voltage to deviate from the phase of the grid voltage depending on the level of the power supplied by the inverter [51-53]. In practice, this means that the inverter seems to supply reactive power into the grid even if the inverter output power is pure real power at PCC [53]. The total apparent power in grid naturally corresponds to the inverter output power. At the point, where the grid power is fully reactive power, the inverter becomes unstable due to trying to take power from the grid, but the switch control scheme of the converter bridge does not usually allow it. In case of grid-connected rectifiers, the same phenomenon will take place, but the direction of the power flow is reversed compared to the inverters [53]. The problem can be solved by modifying the PLL feedback 
controller in such a manner that its reference includes the information from the grid impedance seen from the PCC and the level of grid current [51]. In practice, this means that the grid impedance shall be measured online for modifying the PLL reference [53].

In grid-connected applications, the instability may take place, in principle, at any frequency depending on the behavior of the grid impedance, where the electrical resonances are of interest due to providing zero-degree phase behavior of the grid impedance at the resonant frequency $[12,55,56]$. The negative-incremental-resistance-like behavior of the grid-connected converter may reduce the damping of the grid and thus making it prone to electrical resonances, which may cause harmonic currents to appear [57-60]. The reason for the appearing of harmonic currents in PV applications may be also the inability of the inverter to maintain proper output-current waveforms under low-irradiance conditions in cloudy days, and especially, during the mornings and evenings [61,62].

The main objectives of this paper are to survey the state-of-art in the impedance-based interactions in grid-tied three-phase inverters and to introduce the implicit impedance-like parameters also for the grid-tied three phase converters for facilitating the better understanding of these phenomena, which are observed to take place in practical applications as well [63]. The main outcomes of the paper are the explicit proving that the cross-couplings of the impedance elements have to be taken into account for obtaining valid information on the state of stability as well as that the determinant of the impedance-ratio-based multivariable characteristic polynomial provides the most accurate information on the state of stability.

The rest of the paper is organized as follows: An introduction to the source and load-effect formulations for the grid-tied three-phase inverters are given in Section 2. Experimental and simulated evidence supporting the theoretical findings are given in Section 3, and the conclusions are finally drawn in Section 4.

\section{Theoretical Formulation of Source and Load-Impedance Interactions}

The grid-connected renewable energy systems have to be able to operate in grid-feeding, grid-supporting, and grid-forming modes $[64,65]$ as well as performing smooth transfer between the grid-feeding and grid-forming modes of operation [66]. In grid-feeding and grid-supporting modes, the outmost feedback loops are taken from the input terminal of the converter (cf. Figure 3a, outer loop) [65,67]. In grid-forming mode, all the feedback loops are taken from the output terminal of the converter (cf. Figure 3, inner and outer loops) [64,65]. The photovoltaic (PVG) and wind energy (WEG) generators are known to be internally current-type input sources for power electronic converters [68-71]. Therefore, the input-terminal feedback is taken from the input-terminal voltage as illustrated in Figure 3a. Both of the renewable energy sources are known to be maximum-power-limited sources having one (i.e., WEG, PVG)) [72,73] or more (PVG) [74,75] maximum power points (MPP) at their power-voltage (PV) curves. In grid-feeding mode, when the feedback control is taken from the input-terminal variable [73], the input impedance of the converter usually stays passive, and therefore, the well-designed cascaded system composing of the energy source and the converter is stable. In grid-forming mode, when the outmost feedback is taken from the output-terminal variable $[27,41-43,65,73]$, the input impedance of the converter will exhibit negative incremental-resistor-like characteristics [12]. In this case, the instability will take place, when the operating point of the converter enters into the MPP of the input energy source [69-77].

In order to understand the impedance-originated stability and performance-interaction phenomena, the analytical formulation of the corresponding source and load interactions will be derived in the subsequent sections based on the transfer functions of the associated converters and the interaction formulation proposed by Middlebrook in References [6,7]. In case of three-phase converters, the special impedance-like parameters are also of multivariable nature having direct $(\mathrm{d})$ and quadrature (q) components as well as cross-coupling terms between the $\mathrm{d}$ and q components. In renewable energy applications, the input source of the converters is usually DC voltage, and therefore, the source output and converter input impedances are not of multivariable nature. Consequently, 
the source-interaction-related special impedance-like parameters can be solved quite easily in analytical forms as well. The three-phase grid connection means that all the load-interaction-related special impedance-like parameters will be of multivariable nature. The solving of the special impedance-like parameters in analytical forms will be very complicated due to the high complexity of the multivariable impedance-based sensitivity functions. Therefore, we will present those special parameters by neglecting the cross-coupling terms for giving the reader an idea of the nature of the load-interaction-related special parameters. The source and load-affected transfer functions can be solved easily in numerical forms by using, for example, Matlab ${ }^{\mathrm{TM}}$ as demonstrated in [12].

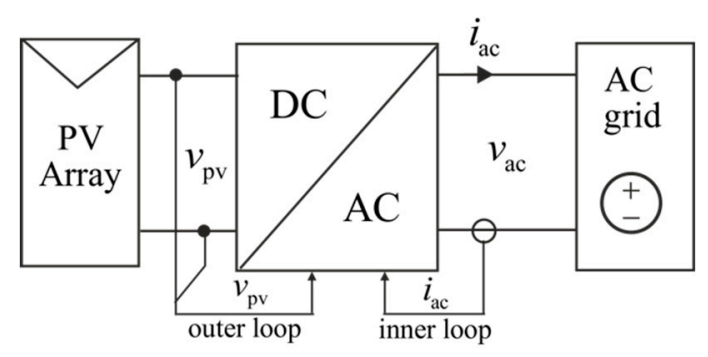

(a)

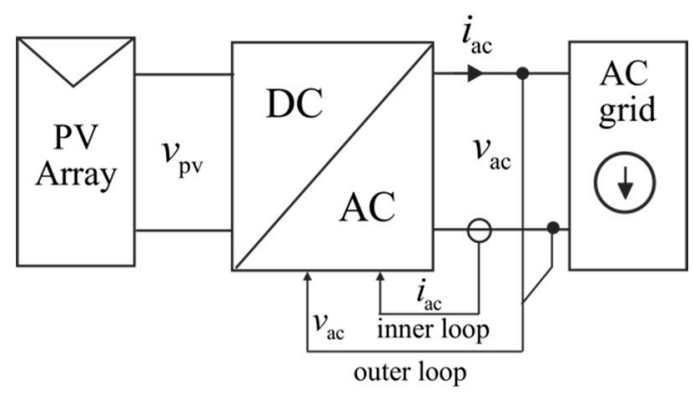

(b)

Figure 3. Operation modes of single-stage grid-connected PV energy system: (a) grid-feeding/ supporting mode, and (b) grid-forming mode.

\subsection{Three-Phase VF-VO Inverter}

The voltage-fed (VF) voltage-output (VO) inverter is used in the grid-forming-mode renewable energy systems (cf. Figure 3b), where the inverter takes care both the grid voltage and frequency. The loads connected to the grid will determine the power level and type of the inverter. In renewable energy applications, the input-terminal source is a voltage-type source, and the output terminal source is a three-phase current-type sink, respectively.

The transfer functions of the three-phase converters are given in synchronous reference frame or $\mathrm{dq}$ frame due to the multivariable nature of the converter $[12,22]$ as

$$
\left[\begin{array}{c}
\hat{i}_{\text {in }} \\
\hat{v}_{\mathrm{o}-\mathrm{d}} \\
\hat{v}_{\mathrm{o}-\mathrm{q}}
\end{array}\right]=\left[\begin{array}{ccccc}
Y_{\mathrm{in}} & T_{\mathrm{oi}-\mathrm{d}} & T_{\mathrm{oi}-\mathrm{q}} & G_{\mathrm{ci}-\mathrm{d}} & G_{\mathrm{ci}-\mathrm{q}} \\
G_{\mathrm{io}-\mathrm{d}} & -Z_{\mathrm{o}-\mathrm{d}} & -Z_{\mathrm{o}-\mathrm{qd}} & G_{\mathrm{co}-\mathrm{d}} & G_{\mathrm{co}-\mathrm{qd}} \\
G_{\mathrm{io}-\mathrm{q}} & -Z_{\mathrm{o}-\mathrm{dq}} & -Z_{\mathrm{o}-\mathrm{q}} & G_{\mathrm{co}-\mathrm{dq}} & G_{\mathrm{co}-\mathrm{q}}
\end{array}\right]\left[\begin{array}{c}
\hat{v}_{\text {in }} \\
\hat{i}_{\mathrm{o}-\mathrm{d}} \\
\hat{\mathrm{i}}_{\mathrm{o}-\mathrm{q}} \\
\hat{d}_{\mathrm{d}} \\
\hat{d}_{\mathrm{q}}
\end{array}\right]
$$

where the right-side vector contains the input variables, and the left-side vector the output variables, respectively. Equation (2) denotes actually a set of simultaneous equations, which define explicitly the transfer functions in the transfer function matrix. As an example, the element $(1,1)$ of the transfer function known as the input admittance $\left(Y_{\text {in }}\right)$ of the converter describes the relation $\hat{i}_{\text {in }} / \hat{v}_{\text {in }}$. The other transfer functions can be expressed in a similar manner following the rule dictated by $\hat{i}_{\text {in }} / \hat{v}_{\text {in }}$. The hat over the input and output variables denotes that the variables are small-signal variables.

Equation (2) can be formulated into a multivariable form according to Reference [12] as shown in Equations (3) and (4). The minus sign in front of the element $(2,2)$ in Equation (4) is the consequence of the selected output-terminal-current direction (cf. Figure 3). The multivariable-form transfer functions in Equation (4) can be represented also in the form of multivariable linear circuit as given in Figure 4. The linear circuit can be utilized effectively to solve the source and load-affected transfer functions in multivariable form. 


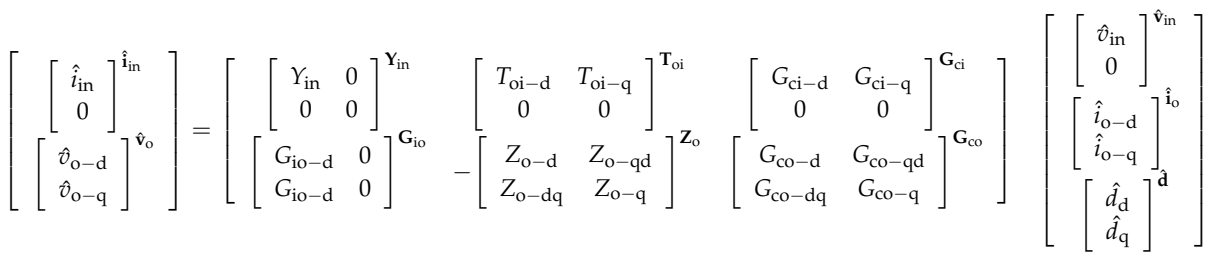

$$
\begin{aligned}
& {\left[\begin{array}{c}
\hat{\mathbf{i}}_{\text {in }} \\
\hat{\mathbf{v}}_{\mathrm{O}}
\end{array}\right]=\left[\begin{array}{ccc}
\mathbf{Y}_{\text {in }} & \mathbf{T}_{\mathrm{oi}} & \mathbf{G}_{\mathrm{ci}} \\
\mathbf{G}_{\mathrm{io}} & -\mathbf{Z}_{\mathrm{O}} & \mathbf{G}_{\mathrm{co}}
\end{array}\right]\left[\begin{array}{c}
\hat{\mathbf{v}}_{\text {in }} \\
\hat{\mathbf{i}}_{\mathrm{O}} \\
\hat{\mathbf{d}}
\end{array}\right]}
\end{aligned}
$$

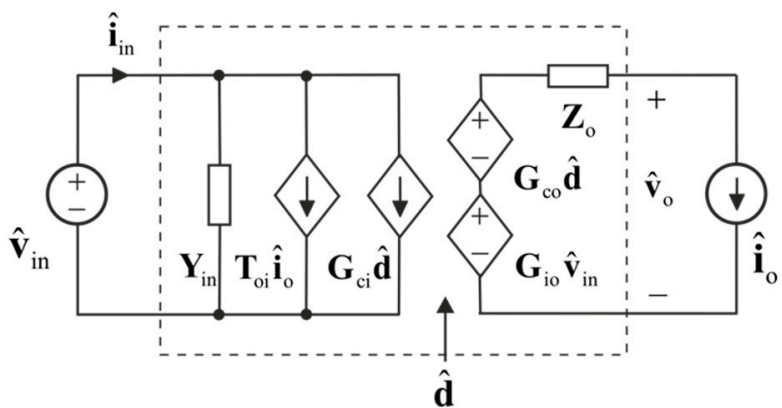

Figure 4. Linear multi-variable equivalent circuit of three-phase VF-VO DC-AC converter.

\subsubsection{Source-Affected Transfer Functions}

Figure 5 shows the corresponding equivalent circuit of Figure 4, when the converter is supplied by a non-ideal input source. According to Figure 5, the original input voltage $\hat{\mathbf{v}}_{\text {in }}$ is changed as

$$
\hat{\mathbf{v}}_{\text {in }}=\hat{\mathbf{v}}_{\text {inS }}-\mathbf{Z}_{\text {inS }} \hat{\mathbf{i}}_{\text {in }}
$$

and

$$
\hat{\mathbf{v}}_{\text {in }}=\left[\mathbf{I}+\mathbf{Z}_{\text {inS }} \mathbf{Y}_{\text {in }}\right]^{-1} \hat{\mathbf{v}}_{\text {inS }}-\left[\mathbf{I}+\mathbf{Z}_{\text {inS }} \mathbf{Y}_{\text {in }}\right]^{-1} \mathbf{Z}_{\mathrm{inS}} \mathbf{T}_{\mathrm{oi}} \hat{\mathbf{i}}_{\mathrm{o}}-\left[\mathbf{I}+\mathbf{Z}_{\text {inS }} \mathbf{Y}_{\text {in }}\right]^{-1} \mathbf{Z}_{\text {inS }} \mathbf{G}_{\mathrm{ci}} \hat{\mathbf{d}}
$$

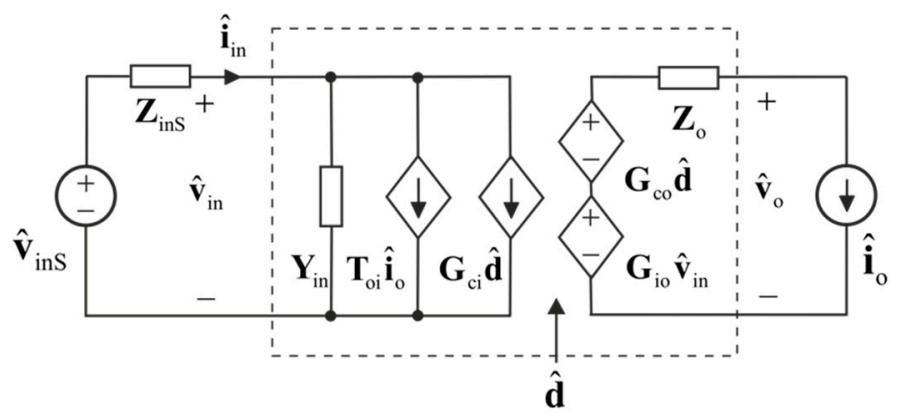

Figure 5. Linear multi-variable equivalent circuit of three-phase VF-VO DC-AC converter with a non-ideal source.

The source-affected set of multi-variable transfer functions can be obtained by replacing $\hat{\mathbf{v}}_{\text {in }}$ in the upper row of Equation (4) by Equation (5) and in the bottom row of Equation (4) by Equation (6), respectively. These procedures yield the set of source-affected transfer functions as

$$
\begin{aligned}
& {\left[\begin{array}{c}
\hat{\mathbf{i}}_{\text {in }} \\
\hat{\mathbf{v}}_{\mathrm{O}}
\end{array}\right]=\left[\begin{array}{ccc}
\mathbf{Y}_{\text {in }}^{\mathrm{S}} & \mathbf{T}_{\mathrm{oi}}^{\mathrm{S}} & \mathbf{G}_{\mathrm{ci}}^{\mathrm{S}} \\
\mathbf{G}_{\mathrm{io}}^{\mathrm{S}} & -\mathbf{Z}_{\mathrm{o}}^{\mathrm{S}} & \mathbf{G}_{\mathrm{co}}^{\mathrm{S}}
\end{array}\right]\left[\begin{array}{c}
\hat{\mathbf{v}}_{\text {ins }} \\
\hat{\mathbf{i}}_{\mathrm{o}} \\
\hat{\mathbf{d}}
\end{array}\right]} \\
& {\left[\begin{array}{c}
\hat{\mathbf{i}}_{\text {in }} \\
\hat{\mathbf{v}}_{\mathrm{o}}
\end{array}\right]=\left[\begin{array}{ccc}
{\left[\mathbf{I}+\mathbf{Y}_{\text {in }} \mathbf{Z}_{\text {ins }}\right]^{-1} \mathbf{Y}_{\text {in }}} & {\left[\mathbf{I}+\mathbf{Y}_{\text {in }} \mathbf{Z}_{\text {ins }}\right]^{-1} \mathbf{T}_{\text {oi }}} & {\left[\mathbf{I}+\mathbf{Y}_{\text {in }} \mathbf{Z}_{\text {inS }}\right]^{-1} \mathbf{G}_{\mathrm{ci}}} \\
\mathbf{G}_{\text {io }}\left[\mathbf{I}+\mathbf{Z}_{\text {inS }} \mathbf{Y}_{\text {in }}\right]^{-1} & -\left(\mathbf{Z}_{\mathrm{o}}+\mathbf{G}_{\text {io }}\left[\mathbf{I}+\mathbf{Z}_{\text {ins }} \mathbf{Y}_{\text {in }}\right]^{-1} \mathbf{Z}_{\text {inS }} \mathbf{T}_{\mathrm{oi}}\right) & \mathbf{G}_{\mathrm{co}}-\mathbf{G}_{\text {io }}\left[\mathbf{I}+\mathbf{Z}_{\text {inS }} \mathbf{Y}_{\text {in }}\right]^{-1} \mathbf{Z}_{\text {ins }} \mathbf{G}_{\mathrm{ci}}
\end{array}\right]\left[\begin{array}{c}
\hat{\mathbf{v}}_{\text {ins }} \\
\hat{\mathbf{i}}_{\mathrm{o}} \\
\hat{\mathbf{d}}
\end{array}\right]}
\end{aligned}
$$


Equation (7) shows that the input dynamics of the inverter (i.e., the elements $(1,1),(1,2)$ and $(1,3)$ in Equation (4)) and the input-to-output transfer function $\mathbf{G}_{\text {io }}$ (i.e., the element $(2,1)$ in Equation (4)) are affected only via the impedance-based sensitivity function $\left[\mathbf{I}+\mathbf{Y}_{\text {in }} \mathbf{Z}_{\text {inS }}\right]^{-1}$ or $\left[\mathbf{I}+\mathbf{Z}_{\text {inS }} \mathbf{Y}_{\text {in }}\right]^{-1}$. It may be also obvious that the stability of the cascaded source-converter system can be assessed by means of $\left[\mathbf{I}+\mathbf{Y}_{\text {in }} \mathbf{Z}_{\text {ins }}\right]^{-1}$ and $\left[\mathbf{I}+\mathbf{Z}_{\text {inS }} \mathbf{Y}_{\text {in }}\right]^{-1}$ by applying the generalized Nyquist stability criterion $[27,28]$. The output impedance $\left(\mathbf{Z}_{\mathrm{o}}\right)$ (i.e., the element $(2,2)$ in Equation (4)) and the control-to-output-voltage transfer function $\left(\mathbf{G}_{\mathrm{co}}\right)$ (i.e., the element $(2,3)$ in Equation $\left.(4)\right)$ are affected via the impedance-based sensitivity function $\left[\mathbf{I}+\mathbf{Z}_{\text {ins }} \mathbf{Y}_{\text {in }}\right]^{-1}$ as well as via a certain numerator polynomial, which contains, in general case, a multivariable impedance-admittance product. One of the multivariable elements, in this product, is the multivariable special parameter, which cannot be extracted directly from the matrix formulas in Equation (7), because the matrix equations cannot be manipulated into the EET form given in Equation (1) (Section 1). The special impedance parameters are known as input admittance at

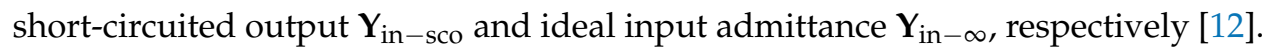

In this specific case, when the input source is a DC source, all the special parameters can be solved analytically as they are, because $\left[\mathbf{I}+\mathbf{Y}_{\text {in }} \mathbf{Z}_{\text {ins }}\right]^{-1}$ and $\left[\mathbf{I}+\mathbf{Z}_{\text {ins }} \mathbf{Y}_{\text {in }}\right]^{-1}$ can be given by

$$
\left[\begin{array}{cc}
\frac{1}{1+Z_{\text {ins }} Y_{\text {in }}} & 0 \\
0 & 1
\end{array}\right]
$$

According to Equations (3), (7), and (8), we can compute the source-affected transfer functions to be

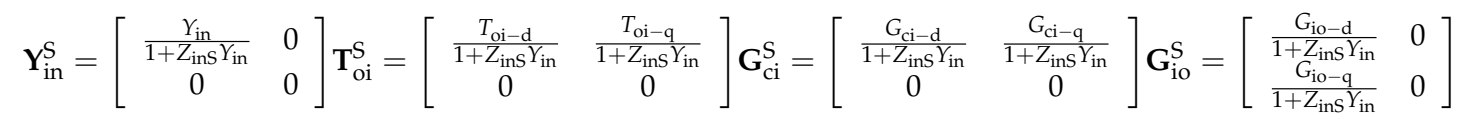

and

$$
\mathbf{Z}_{\mathrm{o}}^{S}=\left[\begin{array}{cc}
\frac{1+Z_{\text {ins }} Y_{\text {in }- \text { sco-d }}}{1+Z_{\text {in }} Y_{\text {in }}} Z_{\mathrm{o}-\mathrm{d}} & \frac{1+Z_{\text {inS }} Y_{\text {in }- \text { sco-qd }}}{1+Z_{\text {ins }} Y_{\text {in }}} Z_{\mathrm{o}-\mathrm{qd}} \\
\frac{1+Z_{\text {ins }} Y_{\text {in }- \text { sco-dq }}}{1+Z_{\text {inS }} Y_{\text {in }}} Z_{\mathrm{o}-\mathrm{dq}} & \frac{1+Z_{\text {ins }} Y_{\text {in }- \text { sco-q }}}{1+Z_{\text {ins }} Y_{\text {in }}} Z_{\mathrm{o}-\mathrm{q}}
\end{array}\right]
$$

where

$$
\mathbf{Y}_{\text {in-sco }}=\left[\begin{array}{cc}
Y_{\text {in-sco-d }} & Y_{\text {in-sco-qd }} \\
Y_{\text {in-sco-dq }} & Y_{\text {in-sco-q }}
\end{array}\right]=\left[\begin{array}{cc}
Y_{\text {in }}+\frac{G_{\text {io-d }} T_{\text {oi-d }}}{Z_{\mathrm{o}-\mathrm{d}}} & Y_{\text {in }}+\frac{G_{\text {io-d }} T_{\text {oi }-q}}{Z_{\text {o-qd }}} \\
Y_{\text {in }}+\frac{G_{\text {io- }} T_{\text {oi-d }}}{Z_{\text {o-dq }}} & Y_{\text {in }}+\frac{G_{\text {io-q }} T_{\text {oi }-q}}{Z_{\text {o-q }}}
\end{array}\right]
$$

as well as

$$
\mathbf{G}_{\mathrm{co}}^{\mathrm{S}}=\left[\begin{array}{cc}
\frac{1+Z_{\text {ins }} Y_{\text {in }-\infty-\mathrm{d}}}{1+Z_{\text {ins }} Y_{\text {in }}} G_{\mathrm{co}-\mathrm{d}} & \frac{1+Z_{\text {ins }} Y_{\text {in }-\infty-\mathrm{qd}}}{1+Z_{\text {in }} Y_{\text {in }}} G_{\mathrm{co}-\mathrm{qd}} \\
\frac{1+Z_{\text {ins }} Y_{\text {in }-\infty-\mathrm{dq}}}{1+Z_{\text {ins }} Y_{\text {in }}} G_{\mathrm{co}-\mathrm{dq}} & \frac{1+Z_{\text {ins }} Y_{\text {in }-\infty-\mathrm{q}}}{1+Z_{\text {inS }} Y_{\text {in }}} G_{\mathrm{co}-\mathrm{q}}
\end{array}\right]
$$

where

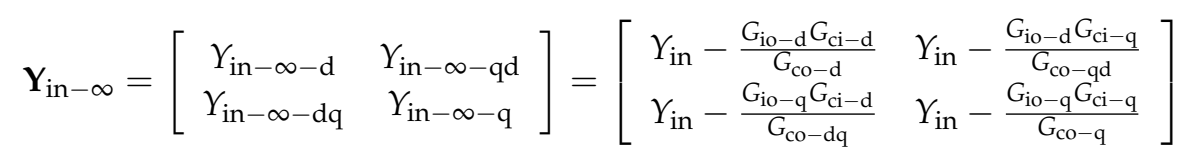

The expressions of the special parameters in Equations (11) and (13) equal the expressions defined for the corresponding DC-DC converters as explicitly given in Reference ([12], p. 143, Equation (3.32)).

\subsubsection{Load-Affected Transfer Functions}

Figure 6 shows the VF-VO inverter (cf. Figure 4) connected to the power grid via the PCC, where the power grid is represented by a generalized multivariable load system. It may be obvious that the interface at the output terminal of the load system (i.e., the terminal designated by $\hat{\mathbf{v}}_{\mathrm{oL}}$ ) is not accessible in general and therefore, the input admittance $\left(\mathbf{Y}_{\mathrm{inL}}\right)$ is the only measurable transfer function. As a consequence, we consider the equivalent circuit of the power grid to be composed of its 
input admittance denoted as $\mathbf{Y}_{\mathrm{oL}}$ (i.e., $\mathbf{Y}_{\mathrm{inL}}$ in Figure 6) and the constant-current sink denoted as $\hat{\mathbf{i}}_{\mathrm{oL}}$ (i.e., $\mathrm{Z}_{\mathrm{oL}}=0, \mathrm{G}_{\mathrm{ioL}}=\mathrm{T}_{\mathrm{oiL}}=1$ ).

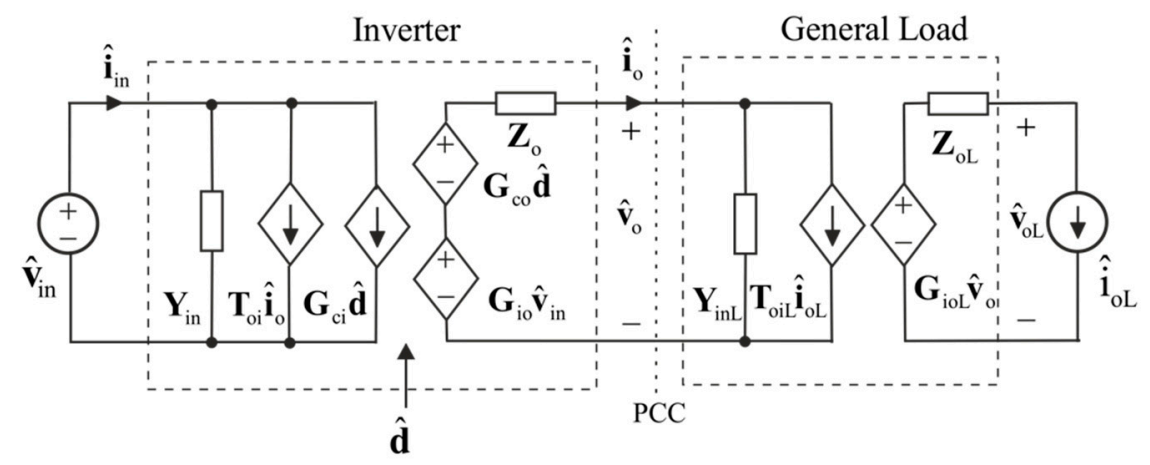

Figure 6. The VF-VO inverter connected to a generalized power grid.

Figure 7 shows the equivalent circuit of the converter in Figure 4, when it is terminated with a non-ideal load. According to Figure 7, the original output current $\hat{\mathbf{i}}_{\mathrm{o}}$ is changed as

$$
\hat{\mathbf{i}}_{\mathrm{O}}=\hat{\mathbf{i}}_{\mathrm{OL}}+\mathbf{Y}_{\mathrm{oL}} \hat{\mathbf{v}}_{\mathrm{O}}
$$

and

$$
\hat{\mathbf{i}}_{\mathrm{O}}=\left[\mathbf{I}+\mathbf{Y}_{\mathrm{oL}} \mathbf{Z}_{\mathrm{o}}\right]^{-1} \hat{\mathbf{i}}_{\mathrm{oL}}+\left[\mathbf{I}+\mathbf{Y}_{\mathrm{oL}} \mathbf{Z}_{\mathrm{o}}\right]^{-1} \mathbf{Y}_{\mathrm{oL}} \mathbf{G}_{\mathrm{io}} \hat{\mathbf{v}}_{\mathrm{in}}+\left[\mathbf{I}+\mathbf{Y}_{\mathrm{oL}} \mathbf{Z}_{\mathrm{o}}\right]^{-1} \mathbf{Y}_{\mathrm{oL}} \mathbf{G}_{\mathrm{co}} \hat{\mathbf{d}}
$$

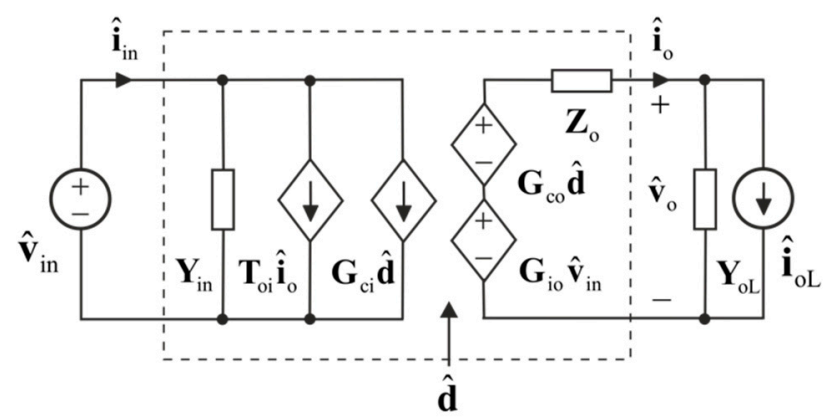

Figure 7. Linear multi-variable equivalent circuit of three-phase VF-VO DC-AC converter with a non-ideal load.

The load-affected set of transfer functions can be obtained by replacing $\hat{\mathbf{i}}_{\mathrm{o}}$ in the bottom row of Equation (4) by Equation (14) and in the upper row of Equation (4) by Equation (15), respectively. These procedures yield the set of load-affected transfer functions as

$$
\begin{aligned}
& {\left[\begin{array}{l}
\hat{\mathbf{i}}_{\mathrm{in}} \\
\hat{\mathbf{v}}_{\mathrm{o}}
\end{array}\right]=\left[\begin{array}{ccc}
\mathbf{Y}_{\mathrm{in}}^{\mathrm{L}} & \mathbf{T}_{\mathrm{oi}}^{\mathrm{L}} & \mathbf{G}_{\mathrm{ci}}^{\mathrm{L}} \\
\mathbf{G}_{\mathrm{io}}^{\mathrm{L}} & -\mathbf{Z}_{\mathrm{o}}^{\mathrm{L}} & \mathbf{G}_{\mathrm{co}}^{\mathrm{L}}
\end{array}\right]\left[\begin{array}{c}
\hat{\mathrm{v}}_{\mathrm{in}} \\
\hat{\mathrm{i}}_{\mathrm{oL}} \\
\hat{\mathbf{d}}
\end{array}\right]} \\
& {\left[\begin{array}{c}
\hat{\mathrm{i}}_{\mathrm{in}} \\
\hat{\mathbf{v}}_{\mathrm{o}}
\end{array}\right]=\left[\begin{array}{ccc}
\mathbf{Y}_{\mathrm{in}}+\mathbf{T}_{\mathrm{oi}}\left[\mathbf{I}+\mathbf{Y}_{\mathrm{oL}} \mathbf{Z}_{\mathrm{o}}\right]^{-1} \mathbf{Y}_{\mathrm{oL}} \mathbf{G}_{\mathrm{io}} & \mathbf{T}_{\mathrm{oi}}\left[\mathbf{I}+\mathbf{Y}_{\mathrm{oL}} \mathbf{Z}_{\mathrm{o}}\right]^{-1} & \mathbf{G}_{\mathrm{ci}}+\mathbf{T}_{\mathrm{oi}}\left[\mathbf{I}+\mathbf{Y}_{\mathrm{oL}} \mathbf{Z}_{\mathrm{o}}\right]^{-1} \mathbf{Y}_{\mathrm{oL}} \mathbf{G}_{\mathrm{co}} \\
{\left[\mathbf{I}+\mathbf{Z}_{\mathrm{o}} \mathbf{Y}_{\mathrm{oL}}\right]^{-1} \mathbf{G}_{\mathrm{io}}} & -\left[\mathbf{I}+\mathbf{Z}_{\mathrm{o}} \mathbf{Y}_{\mathrm{oL}}\right]^{-1} \mathbf{Z}_{\mathrm{o}} & {\left[\mathbf{I}+\mathbf{Z}_{\mathrm{o}} \mathbf{Y}_{\mathrm{oL}}\right]^{-1} \mathbf{G}_{\mathrm{co}}}
\end{array}\right]\left[\begin{array}{c}
\hat{\mathrm{v}}_{\mathrm{in}} \\
\hat{\mathbf{i}}_{\mathrm{oL}} \\
\hat{\mathbf{d}}
\end{array}\right]}
\end{aligned}
$$

The load-affected multivariable transfer functions in Equation (16) can be solved easily with a proper software package such as Matlab ${ }^{\mathrm{TM}}$ in numerical form. As shown in (3), both $\mathbf{Z}_{\mathrm{o}}$ and $\mathbf{Y}_{\mathrm{oL}}$ comprise of four distinct transfer functions, which makes $\left[\mathbf{I}+\mathbf{Z}_{\mathrm{O}} \mathbf{Y}_{\mathrm{oL}}\right]^{-1}$ and $\left[\mathbf{I}+\mathbf{Y}_{\mathrm{oL}} \mathbf{Z}_{\mathrm{O}}\right]^{-1}$ to be rather complicated in analytic form, and therefore, the further processing of the multivariable transfer functions in Equation (16) similarly as performed in Equations (9)-(13) is almost impossible although the elements $(1,2),(2,1)-(2,3)$ in Equation $(16)$ seem to be very simple. The elements $(1,1)$ and $(1,3)$ in Equation $(16)$ include certain impedance-like special parameters, which are known as output 
impedances at open-circuit input terminal $\mathbf{Z}_{\mathrm{o}-\text { oci }}(1,1)$ and ideal output impedance $\mathbf{Z}_{\mathrm{o}-\infty}(1,3)$ [12], respectively. The elements $(1,1)$ and $(1,3)$ cannot be, however, put into the EET-method form according to Equation (1), and therefore, $\mathbf{Z}_{\mathrm{O}-\mathrm{oci}}$ and $\mathbf{Z}_{\mathrm{O}-\infty}$ cannot be found as a full-order matrix equation. It shall be observed that all the transfer functions in Equation (16) related to $\hat{\mathbf{i}}_{\mathrm{oL}}$ are not real in practice as discussed above.

We will give, in this paper, the load-affected transfer functions in Equation (16) by omitting the cross- coupling terms in $\mathbf{Z}_{\mathrm{O}}$ and $\mathbf{Y}_{\mathrm{oL}}$. Thus $\left[\mathbf{I}+\mathbf{Z}_{\mathrm{O}} \mathbf{Y}_{\mathrm{oL}}\right]^{-1}$ can be given by

$$
\left[\begin{array}{cc}
\frac{1}{1+Z_{\mathrm{o}-\mathrm{d}} Y_{\mathrm{oL}-\mathrm{d}}} & 0 \\
0 & \frac{1}{1+Z_{\mathrm{o}-\mathrm{q}} Y_{\mathrm{oL}-\mathrm{q}}}
\end{array}\right]
$$

According to Equations (3), (16), and (17), we can compute the load-affected transfer functions to be

$$
\begin{aligned}
& \mathbf{G}_{\mathrm{io}}^{\mathrm{L}}=\left[\begin{array}{cc}
\frac{G_{\mathrm{io}-\mathrm{d}}}{1+Z_{\mathrm{o}-\mathrm{d}} Y_{\mathrm{oL}-\mathrm{d}}} & 0 \\
\frac{\mathrm{G}_{\mathrm{io}-\mathrm{q}}}{1+Z_{\mathrm{o}-\mathrm{q}} Y_{\mathrm{oL}-\mathrm{q}}} & 0
\end{array}\right] \mathbf{Z}_{\mathrm{o}}^{\mathrm{L}}=\left[\begin{array}{cc}
\frac{Z_{\mathrm{o}-\mathrm{d}}}{1+Z_{\mathrm{o}-\mathrm{d}} Y_{\mathrm{oL}-\mathrm{d}}} & 0 \\
0 & \frac{Z_{\mathrm{o}-\mathrm{q}}}{1+Z_{\mathrm{o}-\mathrm{q}} Y_{\mathrm{oL}-\mathrm{q}}}
\end{array}\right] \mathbf{G}_{\mathrm{co}}^{\mathrm{L}}=\left[\begin{array}{cc}
\frac{G_{\mathrm{co}-\mathrm{d}}}{1+Z_{\mathrm{o}-\mathrm{d}} Y_{\mathrm{oL}-\mathrm{d}}} & \frac{G_{\mathrm{co}-\mathrm{qd}}}{1+Z_{\mathrm{o}-\mathrm{d}} Y_{\mathrm{oL}-\mathrm{d}}} \\
\frac{G_{\mathrm{co}-\mathrm{dq}}}{1+Z_{\mathrm{o}-\mathrm{q}} Y_{\mathrm{oL}-\mathrm{q}}} & \frac{\mathrm{G}_{\mathrm{co}-\mathrm{q}}}{1+Z_{\mathrm{o}-\mathrm{q}} \mathrm{Y}_{\mathrm{oL}-\mathrm{q}}}
\end{array}\right] \\
& \mathbf{T}_{\mathrm{oi}}^{\mathrm{L}}=\left[\begin{array}{cc}
\frac{T_{\mathrm{oi}-\mathrm{d}}}{1+Z_{\mathrm{o}-\mathrm{d}} Y_{\mathrm{oL}-\mathrm{d}}} & \frac{T_{\mathrm{oi}-\mathrm{q}}}{1+Z_{\mathrm{o}-\mathrm{q}} Y_{\mathrm{oL}-\mathrm{q}}} \\
0 & 0
\end{array}\right]
\end{aligned}
$$

and

$$
\mathbf{Y}_{\text {in }}^{\mathrm{L}}=\left[\begin{array}{cc}
\left(\frac{1+Y_{\mathrm{oL}-\mathrm{d}} Z_{\mathrm{o}-\mathrm{oci}-\mathrm{d}}}{1+Y_{\mathrm{oL}-\mathrm{d}} Z_{\mathrm{o}-\mathrm{d}}}+\frac{1+Y_{\mathrm{oL}-\mathrm{q}} Z_{\mathrm{o}-\mathrm{oci}-\mathrm{q}}}{1+Y_{\mathrm{oL}-\mathrm{q}} Z_{\mathrm{o}-\mathrm{q}}}-1\right) Y_{\text {in }} & 0 \\
0 & 0
\end{array}\right]
$$

where

$$
\mathbf{Z}_{\mathrm{o}-\mathrm{oci}}=\left[\begin{array}{cc}
Z_{\mathrm{o}-\mathrm{oci}-\mathrm{d}} & 0 \\
0 & Z_{\mathrm{o}-\mathrm{oci}-\mathrm{q}}
\end{array}\right]=\left[\begin{array}{cc}
Z_{\mathrm{o}-\mathrm{d}}+\frac{G_{\mathrm{io}-\mathrm{d}} T_{\mathrm{oi}-\mathrm{d}}}{Y_{\text {in }}} & 0 \\
0 & Z_{\mathrm{o}-\mathrm{q}}+\frac{G_{\mathrm{io}-\mathrm{q}} T_{\mathrm{oi}-\mathrm{q}}}{Y_{\text {in }}}
\end{array}\right]
$$

as well as

$$
\mathbf{G}_{\mathrm{ci}}^{\mathrm{L}}=\left[\begin{array}{cc}
\left(\frac{1+Y_{\mathrm{oL}-\mathrm{d}} Z_{\mathrm{o}-\infty-\mathrm{d}}}{1+Y_{\mathrm{oL}-\mathrm{d}} Z_{\mathrm{o}-\mathrm{d}}}+\frac{1+Y_{\mathrm{oL}-\mathrm{q}} Z_{\mathrm{o}-\infty-\mathrm{dq}}}{1+Y_{\mathrm{oL}-\mathrm{q}} Z_{\mathrm{o}-\mathrm{q}}}-1\right) G_{\mathrm{ci}-\mathrm{d}} & \left(\frac{1+Y_{\mathrm{oL}-q} Z_{\mathrm{o}-\infty-\mathrm{q}}}{1+Y_{\mathrm{oL}-\mathrm{q}} Z_{\mathrm{o}-\mathrm{q}}}+\frac{1+Y_{\mathrm{oL}-\mathrm{d}} Z_{\mathrm{o}-\infty-\mathrm{q}}}{1+Y_{\mathrm{oL}-\mathrm{d}} Z_{\mathrm{o}-\mathrm{d}}}-1\right) \mathrm{G}_{\mathrm{ci}-\mathrm{q}} \\
0 & 0
\end{array}\right]
$$

where

$$
\mathbf{Z}_{\mathrm{o}-\infty}=\left[\begin{array}{cc}
Z_{\mathrm{o}-\infty-\mathrm{d}} & Z_{\mathrm{o}-\infty-\mathrm{qd}} \\
Z_{\mathrm{o}-\infty-\mathrm{dq}} & Z_{\mathrm{o}-\infty-\mathrm{q}}
\end{array}\right]=\left[\begin{array}{cc}
Z_{\mathrm{o}-\mathrm{d}}+\frac{T_{\mathrm{oi}-\mathrm{d}} G_{\mathrm{co}-\mathrm{d}}}{G_{\mathrm{ci}-\mathrm{d}}} & Z_{\mathrm{o}-\mathrm{d}}+\frac{T_{\mathrm{oi}-\mathrm{q}} G_{\mathrm{co}-\mathrm{qd}}}{G_{\mathrm{i} i-\mathrm{d}}} \\
Z_{\mathrm{o}-\mathrm{q}}+\frac{T_{\mathrm{oi}-\mathrm{d}} G_{\mathrm{co}-\mathrm{dq}}}{G_{\mathrm{ci}-\mathrm{q}}} & Z_{\mathrm{o}-\mathrm{q}}+\frac{T_{\mathrm{oi}-\mathrm{q}} G_{\mathrm{co}-\mathrm{q}}}{G_{\mathrm{ci}-\mathrm{q}}}
\end{array}\right]
$$

The expressions of the special parameters in Equations (20) and (22) equal the expressions defined for the corresponding DC-DC converters as explicitly given in Reference ([12], p. 143, Equation (3.32)).

\subsection{Three-Phase CF-CO Inverter}

The current-fed (CF) current-output (CO) inverter is used in the grid-feeding-mode renewable energy systems (cf. Figure 3a), where the inverter synchronizes itself in the grid frequency and angle as well as supplies energy into the grid. In renewable energy applications, the input-terminal source is a voltage-type source, and the output terminal source is a three-phase grid, respectively.

The transfer functions of the three-phase converters are given in synchronous reference frame or $\mathrm{dq}$ frame due to the multivariable nature of the converter [12,22] as 


$$
\left[\begin{array}{c}
\hat{v}_{\text {in }} \\
\hat{i}_{\mathrm{o}-\mathrm{d}} \\
\hat{i}_{\mathrm{o}-\mathrm{q}}
\end{array}\right]=\left[\begin{array}{ccccc}
\mathrm{Z}_{\mathrm{in}} & T_{\mathrm{oi}-\mathrm{d}} & T_{\mathrm{oi}-\mathrm{q}} & G_{\mathrm{ci}-\mathrm{d}} & G_{\mathrm{ci}-\mathrm{q}} \\
G_{\mathrm{io}-\mathrm{d}} & -Y_{\mathrm{o}-\mathrm{d}} & -Y_{\mathrm{o}-\mathrm{qd}} & G_{\mathrm{co}-\mathrm{d}} & G_{\mathrm{co}-\mathrm{qd}} \\
G_{\mathrm{io}-\mathrm{q}} & -Y_{\mathrm{o}-\mathrm{dq}} & -Y_{\mathrm{o}-\mathrm{q}} & G_{\mathrm{co}-\mathrm{dq}} & G_{\mathrm{co}-\mathrm{q}}
\end{array}\right]\left[\begin{array}{c}
\hat{i}_{\mathrm{in}} \\
\hat{v}_{\mathrm{o}-\mathrm{d}} \\
\hat{v}_{\mathrm{o}-\mathrm{q}} \\
\hat{d}_{\mathrm{d}} \\
\hat{d}_{\mathrm{q}}
\end{array}\right]
$$

which can be given similarly as Equation (2) (Section 2.1) in multivariable mode as

$$
\left[\begin{array}{c}
\hat{\mathbf{v}}_{\text {in }} \\
\hat{\mathbf{i}}_{\mathrm{o}}
\end{array}\right]=\left[\begin{array}{ccc}
\mathbf{Z}_{\text {in }} & \mathbf{T}_{\mathrm{oi}} & \mathbf{G}_{\mathrm{ci}} \\
\mathbf{G}_{\mathrm{io}} & -\mathbf{Y}_{\mathrm{o}} & \mathbf{G}_{\mathrm{co}}
\end{array}\right]\left[\begin{array}{c}
\hat{\mathbf{i}}_{\text {in }} \\
\hat{\mathbf{v}}_{\mathrm{O}} \\
\hat{\mathbf{d}}
\end{array}\right]
$$

and represented by a linear multivariable equivalent circuit as given in Figure 8.

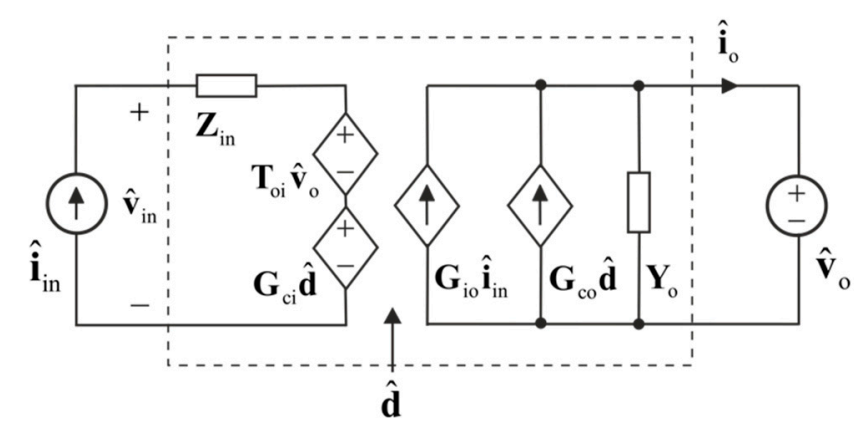

Figure 8. Linear multi-variable equivalent circuit of three-phase CF-CO DC-AC converter.

\subsubsection{Source-Affected Transfer Functions}

Figure 9 shows the corresponding equivalent circuit of Figure 8, when the converter is supplied by a non-ideal input source. According to Figure 9 , the original input current $\hat{\mathbf{i}}_{\text {in }}$ is changed as

$$
\hat{\mathbf{i}}_{\text {in }}=\hat{\mathbf{i}}_{\text {ins }}-\mathbf{Y}_{\text {ins }} \hat{\mathbf{v}}_{\text {in }}
$$

and

$$
\hat{\mathbf{i}}_{\text {in }}=\left[\mathbf{I}+\mathbf{Y}_{\text {inS }} \mathbf{Z}_{\text {in }}\right]^{-1} \hat{\mathbf{i}}_{\text {inS }}-\left[\mathbf{I}+\mathbf{Y}_{\text {ins }} \mathbf{Z}_{\text {in }}\right]^{-1} \mathbf{Y}_{\text {inS }} \mathbf{T}_{\mathrm{i}} \hat{\mathbf{v}}_{\mathrm{o}}-\left[\mathbf{I}+\mathbf{Y}_{\text {ins }} \mathbf{Z}_{\text {in }}\right]^{-1} \mathbf{Y}_{\text {ins }} \mathbf{G}_{\mathrm{ci}} \hat{\mathbf{d}}
$$

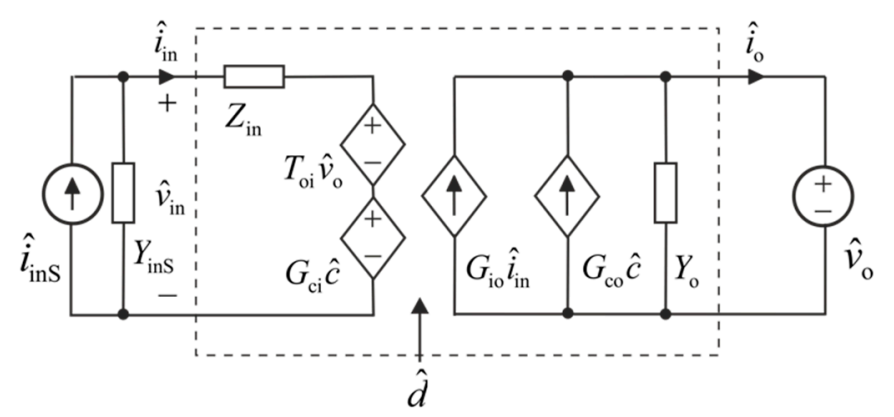

Figure 9. Linear multi-variable equivalent circuit of three-phase CF-CO DC-AC converter with a non-ideal source.

The source-affected set of multi-variable transfer functions can be obtained by replacing $\hat{\mathbf{i}}_{\text {in }}$ in the upper row of Equation (24) by Equation (25) and in the bottom row of Equation (24) by Equation (46), respectively. These procedures yield the set of source-affected transfer functions as 


$$
\begin{aligned}
& {\left[\begin{array}{c}
\hat{\mathbf{v}}_{\text {in }} \\
\hat{\mathbf{i}}_{\mathrm{o}}
\end{array}\right]=\left[\begin{array}{ccc}
\mathbf{Z}_{\mathrm{in}}^{\mathrm{S}} & \mathbf{T}_{\mathrm{oi}}^{\mathrm{S}} & \mathbf{G}_{\mathrm{ci}}^{\mathrm{S}} \\
\mathbf{G}_{\mathrm{io}}^{\mathrm{S}} & -\mathbf{Y}_{\mathrm{o}}^{\mathrm{S}} & \mathbf{G}_{\mathrm{co}}^{\mathrm{S}}
\end{array}\right]\left[\begin{array}{c}
\hat{\mathbf{i}}_{\text {ins }} \\
\hat{\mathbf{v}}_{\mathrm{o}} \\
\hat{\mathbf{d}}
\end{array}\right]} \\
& {\left[\begin{array}{c}
\hat{\mathbf{v}}_{\text {in }} \\
\hat{\mathbf{i}}_{\mathrm{o}}
\end{array}\right]=\left[\begin{array}{ccc}
{\left[\mathbf{I}+\mathbf{Z}_{\text {in }} \mathbf{Y}_{\text {inS }}\right]^{-1} \mathbf{Z}_{\text {in }}} & {\left[\mathbf{I}+\mathbf{Z}_{\text {in }} \mathbf{Y}_{\text {ins }}\right]^{-1} \mathbf{T}_{\text {oi }}} & {\left[\mathbf{I}+\mathbf{Z}_{\text {in }} \mathbf{Y}_{\text {ins }}\right]^{-1} \mathbf{G}_{\text {ci }}} \\
\mathbf{G}_{\text {io }}\left[\mathbf{I}+\mathbf{Y}_{\text {ins }} \mathbf{Z}_{\text {in }}\right]^{-1} & -\left(\mathbf{Y}_{\mathrm{o}}+\mathbf{G}_{\text {io }} \mathbf{Y}_{\text {ins }}\left[\mathbf{I}+\mathbf{Z}_{\text {in }} \mathbf{Y}_{\text {ins }}\right]^{-1} \mathbf{T}_{\mathrm{oi}}\right) & \mathbf{G}_{\mathrm{co}}-\mathbf{G}_{\text {io }} \mathbf{Y}_{\text {ins }}\left[\mathbf{I}+\mathbf{Z}_{\text {in }} \mathbf{Y}_{\text {ins }}\right]^{-1} \mathbf{G}_{\mathrm{ci}}
\end{array}\right]\left[\begin{array}{c}
\hat{\mathbf{i}}_{\text {ins }} \\
\hat{\mathbf{v}}_{\mathrm{o}} \\
\hat{\mathbf{d}}
\end{array}\right]}
\end{aligned}
$$

Equation (27) shows that the input dynamics of the inverter (i.e., the elements $(1,1),(1,2)$ and $(1,3)$ in Equation (24)) and the input-to-output transfer function $\mathbf{G}_{\text {io }}$ (i.e., the element $(2,1)$ in Equation (24)) are affected only via the impedance-based sensitivity function $\left[\mathbf{I}+\mathbf{Z}_{\text {in }} \mathbf{Y}_{\text {ins }}\right]^{-1}$ or $\left[\mathbf{I}+\mathbf{Y}_{\text {ins }} \mathbf{Z}_{\text {in }}\right]^{-1}$. It may be also obvious that the stability of the cascaded source-converter system can be assessed by means of the sensitivity functions by applying the generalized Nyquist stability criterion $[27,28]$. The output impedance $\left(\mathbf{Y}_{\mathrm{o}}\right)$ (i.e., the element $(2,2)$ in Equation $\left.(24)\right)$ and the control-to-output-voltage transfer function $\left(\mathbf{G}_{\mathrm{co}}\right)$ (i.e., the element $(2,3)$ in Equation (24)) are affected via the impedance-based sensitivity function $\left[\mathbf{I}+\mathbf{Z}_{\text {in }} \mathbf{Y}_{\text {ins }}\right]^{-1}$ as well as via a certain numerator polynomial, which contains, in general case, a multivariable impedance-admittance product. One of the multivariable elements, in this product, is the multivariable special parameter, which cannot be extracted directly from the matrix formulas in Equation (27), because they cannot be manipulated into the EET form given in Equation (1) (Section 1). The special impedance-like parameters are known as input impedance at open circuit output $\mathbf{Z}_{\text {in-oco }}$ and ideal input impedance $\mathbf{Z}_{\text {in }-\infty}$.

In this specific case, when the input source is a DC source, all the special parameters can be solved analytically as they are, because $\left[\mathbf{I}+\mathbf{Z}_{\text {in }} \mathbf{Y}_{\text {inS }}\right]^{-1}$ and $\left[\mathbf{I}+\mathbf{Y}_{\text {inS }} \mathbf{Z}_{\text {in }}\right]^{-1}$ can be given as

$$
\left[\begin{array}{cc}
\frac{1}{1+Z_{\text {in }} Y_{\text {inS }}} & 0 \\
0 & 1
\end{array}\right]
$$

According to Equations (23), (27), and (28), we can compute the source-affected transfer functions to be

$$
\mathbf{Z}_{\text {in }}^{\mathrm{S}}=\left[\begin{array}{cc}
\frac{Z_{\text {in }}}{1+Y_{\text {ins }} Z_{\text {in }}} & 0 \\
0 & 0
\end{array}\right] \mathbf{T}_{\mathrm{oi}}^{\mathrm{S}}=\left[\begin{array}{cc}
\frac{T_{\mathrm{oi}-\mathrm{d}}}{1+Y_{\text {ins }} Z_{\text {in }}} & \frac{T_{\mathrm{oi}-\mathrm{q}}}{1+Y_{\text {ins }} Z_{\text {in }}} \\
0 & 0
\end{array}\right] \mathbf{G}_{\mathrm{ci}}^{\mathrm{S}}=\left[\begin{array}{cc}
\frac{G_{\mathrm{ci}-\mathrm{d}}}{1+Y_{\text {ins }} Z_{\text {in }}} & \frac{G_{\mathrm{ci}-\mathrm{q}}}{1+Y_{\text {ins }} Z_{\text {in }}} \\
0 & 0
\end{array}\right] \mathbf{G}_{\mathrm{io}}^{\mathrm{S}}=\left[\begin{array}{cc}
\frac{G_{\text {io-d }}}{1+Y_{\text {ins }} Z_{\text {in }}} & 0 \\
\frac{G_{\text {io }-\mathrm{q}}}{1+Y_{\text {ins }} Z_{\text {in }}} & 0
\end{array}\right]
$$

and

$$
\mathbf{Y}_{\mathrm{o}}^{S}=\left[\begin{array}{cc}
\frac{1+Y_{\text {ins }} Z_{\text {in }- \text { oco-d }}}{1+Y_{\text {ins }} Z_{\text {in }}} Y_{\mathrm{o}-\mathrm{d}} & \frac{1+Y_{\text {ins }} Z_{\text {in }- \text { oco-qd }}}{1+Y_{\text {ins }} Z_{\text {in }}} Y_{\mathrm{o}-\mathrm{qd}} \\
\frac{1+Y_{\text {ins }} Z_{\text {in-oco-dq }}}{1+Y_{\text {ins }} Z_{\text {in }}} Y_{\mathrm{o}-\mathrm{dq}} & \frac{1+Y_{\text {ins }} Z_{\text {in-oco-q }}}{1+Y_{\text {ins }} Z_{\text {in }}} Y_{\mathrm{o}-\mathrm{q}}
\end{array}\right]
$$

where

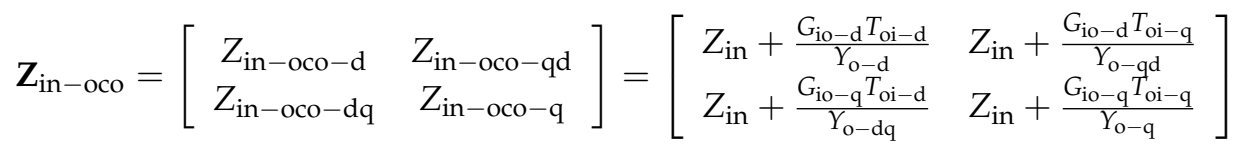

as well as

$$
\mathbf{G}_{\mathrm{co}}^{\mathrm{S}}=\left[\begin{array}{cc}
\frac{1+Y_{\text {ins }} Z_{\text {in }-\infty-\mathrm{d}}}{1+Y_{\text {ins }} Z_{\text {in }}} G_{\mathrm{co}-\mathrm{d}} & \frac{1+Y_{\text {ins }} Z_{\text {in }-\infty-\mathrm{qd}}}{1+Z_{\text {ins }} Y_{\text {in }}} G_{\mathrm{co}-\mathrm{qd}} \\
\frac{1+Y_{\text {ins }} Z_{\text {in }-\infty-\mathrm{dq}}}{1+Y_{\text {ins }} Z_{\text {in }}} G_{\mathrm{co}-\mathrm{dq}} & \frac{1+Y_{\text {ins }} Z_{\text {in }-\infty-\mathrm{q}}}{1+Z_{\text {ins }} Y_{\text {in }}} G_{\mathrm{co}-\mathrm{q}}
\end{array}\right]
$$

where

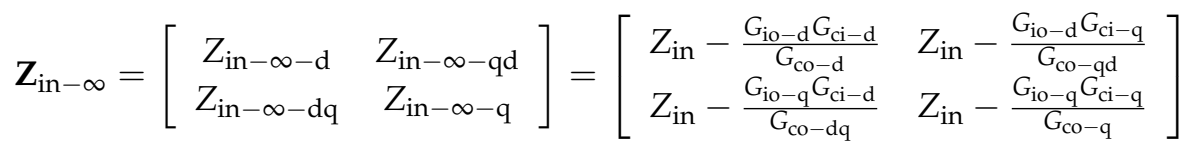

The expressions of the special parameters in Equations (31) and (33) equal the expressions defined for the corresponding DC-DC converters as explicitly given in Reference ([12], p. 356, Equation (8.2)). 


\subsubsection{Load-Affected Transfer Functions}

Figure 10 shows the CF-CO inverter (cf. Figure 8) connected to the power grid via the PCC, where the power grid is represented by a generalized multivariable load system. It may be obvious that the interface at the output terminal of the load system (i.e., the terminal designated by $\hat{\mathbf{i}}_{\mathrm{L}}$ ) is not accessible in general and therefore, the input impedance $\left(\mathbf{Z}_{\text {inL }}\right)$ is the only measurable transfer function. As a consequence, we consider the equivalent circuit of the power grid to be composed of its input impedance denoted as $\mathbf{Z}_{\mathrm{oL}}$ (i.e., $\mathbf{Z}_{\mathrm{inL}}$ ) and the constant-voltage sink denoted as $\hat{\mathbf{v}}_{\mathrm{oL}}$ (i.e., $\mathbf{Y}_{\mathrm{oL}}=0$, $\left.\mathrm{G}_{\mathrm{ioL}}=\mathrm{T}_{\mathrm{oiL}}=1\right)$.

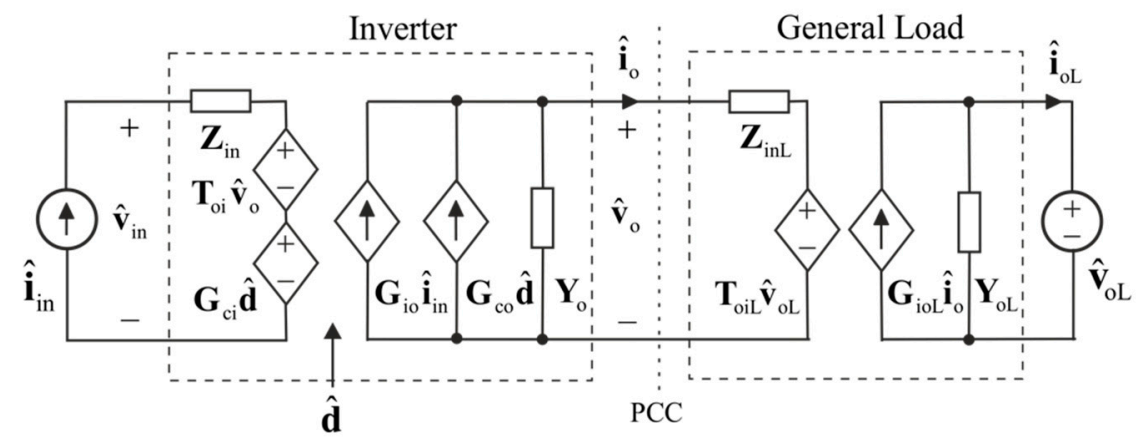

Figure 10. The CF-CO inverter connected to a generalized power grid.

Figure 11 shows the equivalent circuit of the converter in Figure 8, when it is terminated with a non-ideal load. According to Figure 11, the original output current $\hat{\mathbf{v}}_{\mathrm{o}}$ is changed as

$$
\hat{\mathbf{v}}_{\mathrm{O}}=\hat{\mathbf{v}}_{\mathrm{OL}}+\mathbf{Z}_{\mathrm{oL}} \hat{\mathbf{i}}_{\mathrm{O}}
$$

and

$$
\hat{\mathbf{v}}_{\mathrm{o}}=\left[\mathbf{I}+\mathbf{Z}_{\mathrm{oL}} \mathbf{Y}_{\mathrm{o}}\right]^{-1} \hat{\mathbf{v}}_{\mathrm{oL}}+\left[\mathbf{I}+\mathbf{Z}_{\mathrm{oL}} \mathbf{Y}_{\mathrm{o}}\right]^{-1} \mathbf{Z}_{\mathrm{oL}} \mathbf{G}_{\mathrm{io}} \hat{\hat{\mathbf{i}}}_{\mathrm{in}}+\left[\mathbf{I}+\mathbf{Z}_{\mathrm{oL}} \mathbf{Y}_{\mathrm{o}}\right]^{-1} \mathbf{Z}_{\mathrm{oL}} \mathbf{G}_{\mathrm{co}} \hat{\mathbf{d}}
$$

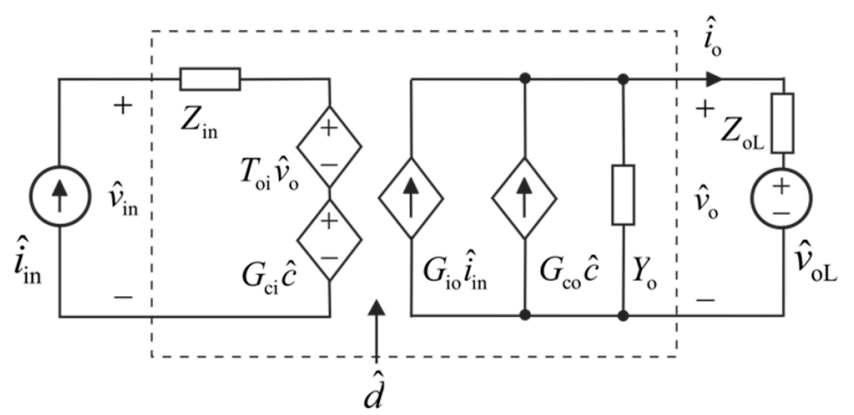

Figure 11. Linear multi-variable equivalent circuit of three-phase CF-CO DC-AC converter with a non-ideal load.

The load-affected set of transfer functions can be obtained by replacing $\hat{\mathbf{v}}_{\mathrm{o}}$ in the bottom row of Equation (24) by Equation (34), and in the upper row of Equation (24) by Equation (35), respectively. These procedures yield the set of load-affected transfer functions as

$$
\begin{aligned}
& {\left[\begin{array}{c}
\hat{v}_{\text {in }} \\
\hat{\mathbf{i}}_{o}
\end{array}\right]=\left[\begin{array}{ccc}
\mathbf{Z}_{\mathrm{in}}^{\mathrm{L}} & \mathbf{T}_{\mathrm{oi}}^{\mathrm{L}} & \mathbf{G}_{\mathrm{ci}}^{\mathrm{L}} \\
\mathbf{G}_{\mathrm{io}}^{\mathrm{L}} & -\mathbf{Y}_{\mathrm{o}}^{\mathrm{L}} & \mathbf{G}_{\mathrm{co}}^{\mathrm{L}}
\end{array}\right]\left[\begin{array}{c}
\hat{\mathrm{i}}_{\mathrm{in}} \\
\hat{\mathbf{v}}_{\mathrm{oL}} \\
\hat{\mathbf{d}}
\end{array}\right]}
\end{aligned}
$$

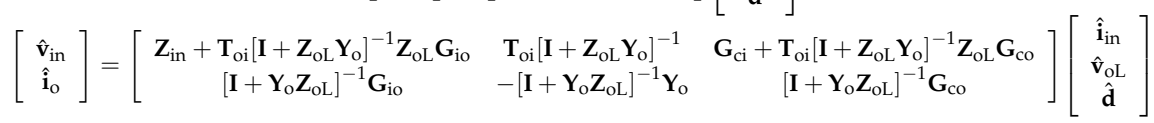

The load-affected multivariable transfer functions in Equation (36) can be solved easily with a proper software package such as Matlab ${ }^{\mathrm{TM}}$ in numerical form. As shown in Equation (23), both $\mathbf{Y}_{\mathrm{o}}$ and 
$\mathbf{Z}_{\mathrm{OL}}$ comprise of four distinct transfer functions, which makes $\left[\mathbf{I}+\mathbf{Y}_{\mathrm{O}} \mathbf{Z}_{\mathrm{OL}}\right]^{-1}$ and $\left[\mathbf{I}+\mathbf{Z}_{\mathrm{oL}} \mathbf{Y}_{\mathrm{O}}\right]^{-1}$ to be rather complicated. As a consequence, the further processing of the multivariable transfer functions in Equation (36) similarly as performed in Equations (30)-(33) is almost impossible although the elements $(1,2),(2,1)-(2,3)$ in Equation (36) seem to be very simple. The elements $(1,1)$ and $(1,3)$ in Equation (36) include certain impedance-like special parameters, which are known as output admittance at short-circuited input terminal $\mathbf{Y}_{\mathrm{o}-\mathrm{sci}}(1,1)$ and ideal output admittance $\mathbf{Y}_{\mathrm{O}-\infty}(1,3)$ [12], respectively.

Equation (36) shows that the output dynamics of the inverter (i.e., the elements $(2,1),(2,2)$ and $(2,3)$ in Equation (24)) and the reverse transfer function $\mathbf{T}_{\text {io }}$ (i.e., the element $(1,2)$ in Equation (24)) are affected only via the impedance-based sensitivity function $\left[\mathbf{I}+\mathbf{Y}_{\mathrm{o}} \mathbf{Z}_{\mathrm{oL}}\right]^{-1}$ or $\left[\mathbf{I}+\mathbf{Z}_{\mathrm{oL}} \mathbf{Y}_{\mathrm{O}}\right]^{-1}$. It may be also obvious that the stability of the cascaded source-converter system can be assessed by means of the sensitivity functions by applying the generalized Nyquist stability criterion $[27,28]$. The input impedance $\left(\mathbf{Z}_{\text {in }}\right)$ (i.e., the element $(1,1)$ in Equation $\left.(24)\right)$ and the control-to-input-voltage transfer function $\left(\mathbf{G}_{\mathrm{ci}}\right)$ (i.e., the element $(1,3)$ in Equation $\left.(24)\right)$ are affected via the impedance-based sensitivity function $\left[\mathbf{I}+\mathbf{Z}_{\mathrm{OL}} \mathbf{Y}_{\mathrm{O}}\right]^{-1}$ as well as via certain numerator polynomials, each of which contain a multivariable impedance-admittance product. One of the multivariable elements, in this product, is the multivariable special parameter, which cannot be extracted directly from the matrix formulas in Equation (36), because they cannot be manipulated into the EET form given in Equation (1) (Section 1). These special impedance-like parameters are known as output admittance at short-circuited input terminal $\left(\mathbf{Y}_{\mathrm{o}-\mathrm{sci}}\right)$ and ideal output admittance $\left(\mathbf{Y}_{\mathrm{O}-\infty}\right)$ [12], respectively. It shall be observed that all the transfer functions in Equation (36) related to $\hat{\mathbf{v}}_{\mathrm{oL}}$ are not real in practice as discussed above.

We will give, in this paper, the load-affected transfer functions in Equation (36) by omitting the cross- coupling terms in $\mathbf{Y}_{\mathrm{O}}$ and $\mathbf{Z}_{\mathrm{oL}}$, which means that both of the sensitivity functions will be equal as well. Therefore $\left[\mathbf{I}+\mathbf{Y}_{\mathrm{o}} \mathrm{Z}_{\mathrm{OL}}\right]^{-1}$ can be given by

$$
\left[\begin{array}{cc}
\frac{1}{1+Y_{\mathrm{o}-\mathrm{d}} Z_{\mathrm{oL}-\mathrm{d}}} & 0 \\
0 & \frac{1}{1+Y_{\mathrm{o}-\mathrm{q}} Z_{\mathrm{oL}-\mathrm{q}}}
\end{array}\right]
$$

According to Equations (23), (36), and (37), we can compute the load-affected transfer functions to be

$$
\begin{aligned}
& \mathbf{G}_{\mathrm{io}}^{\mathrm{L}}=\left[\begin{array}{cc}
\frac{G_{\mathrm{io}-\mathrm{d}}}{1+Y_{\mathrm{o}-\mathrm{d}} Z_{\mathrm{oL}-\mathrm{d}}} & 0 \\
\frac{G_{\mathrm{io}-\mathrm{q}}}{1+Y_{\mathrm{o}-\mathrm{q}} Z_{\mathrm{oL}-\mathrm{q}}} & 0
\end{array}\right] \mathbf{Y}_{\mathrm{o}}^{\mathrm{L}}=\left[\begin{array}{cc}
\frac{Y_{\mathrm{o}-\mathrm{d}}}{1+Y_{\mathrm{o}-\mathrm{d}} Z_{\mathrm{oL}-\mathrm{d}}} & 0 \\
0 & \frac{Y_{\mathrm{o}-\mathrm{q}}}{1+Y_{\mathrm{o}-\mathrm{q}} Z_{\mathrm{oL}-\mathrm{q}}}
\end{array}\right] \mathbf{G}_{\mathrm{co}}^{\mathrm{L}}=\left[\begin{array}{cc}
\frac{G_{\mathrm{co}-\mathrm{d}}}{1+Y_{\mathrm{o}-\mathrm{d}} Z_{\mathrm{oL}-\mathrm{d}}} & \frac{G_{\mathrm{co}-\mathrm{qd}}}{1+Y_{\mathrm{o}-\mathrm{d}} Z_{\mathrm{oL}-\mathrm{d}}} \\
\frac{\mathrm{G}_{\mathrm{co}-\mathrm{dq}}}{1+Y_{\mathrm{o}-\mathrm{q}} Z_{\mathrm{oL}-\mathrm{q}}} & \frac{\mathrm{G}_{\mathrm{co}-\mathrm{q}}}{1+Y_{\mathrm{o}-\mathrm{q}} Z_{\mathrm{oL}-\mathrm{q}}}
\end{array}\right] \\
& \mathbf{T}_{\mathrm{oi}}^{\mathrm{L}}=\left[\begin{array}{cc}
\frac{T_{\mathrm{oi}-\mathrm{d}}}{1+Y_{\mathrm{o}-\mathrm{d}} Z_{\mathrm{oL}-\mathrm{d}}} & \frac{T_{\mathrm{oi}-\mathrm{q}}}{1+Y_{\mathrm{o}-\mathrm{q}} Z_{\mathrm{oL}-\mathrm{q}}} \\
0 & 0
\end{array}\right]
\end{aligned}
$$

and

$$
\mathbf{Z}_{\text {in }}^{\mathrm{L}}=\left[\begin{array}{cc}
\left(\frac{1+Z_{\mathrm{oL}-\mathrm{d}} Y_{\mathrm{o}-\mathrm{sci}-\mathrm{d}}}{1+Y_{\mathrm{o}-\mathrm{d}} Z_{\mathrm{oL}-\mathrm{d}}}+\frac{1+Z_{\mathrm{oL}-\mathrm{q}} Y_{\mathrm{o}-\mathrm{sci}-\mathrm{q}}}{1+Y_{\mathrm{o}-\mathrm{q}} Z_{\mathrm{oL}-\mathrm{q}}}-1\right) Z_{\text {in }} & 0 \\
0 & 0
\end{array}\right]
$$

where

$$
\mathbf{Y}_{\mathrm{o}-\mathrm{sci}}=\left[\begin{array}{cc}
Y_{\mathrm{o}-\mathrm{sci}-\mathrm{d}} & 0 \\
0 & Y_{\mathrm{o}-\mathrm{sci}-\mathrm{q}}
\end{array}\right]=\left[\begin{array}{cc}
Y_{\mathrm{o}-\mathrm{d}}+\frac{G_{\mathrm{io}-\mathrm{d}} T_{\mathrm{oi}-\mathrm{d}}}{Z_{\mathrm{in}}} & 0 \\
0 & Y_{\mathrm{o}-\mathrm{q}}+\frac{G_{\mathrm{io}-\mathrm{q}} T_{\mathrm{oi}-\mathrm{q}}}{Z_{\mathrm{in}}}
\end{array}\right]
$$

as well as

$$
\mathbf{G}_{\mathrm{ci}}^{\mathrm{L}}=\left[\begin{array}{cc}
\left(\frac{1+Z_{\mathrm{oL}-\mathrm{d}} \mathrm{Y}_{\mathrm{o}-\infty-\mathrm{d}}}{1+\mathrm{Z}_{\mathrm{oL}-\mathrm{d}} Y_{\mathrm{o}-\mathrm{d}}}+\frac{1+Z_{\mathrm{oL}-\mathrm{q}} Y_{\mathrm{o}-\infty-\mathrm{dq}}}{1+Z_{\mathrm{oL}-\mathrm{q}} Y_{\mathrm{o}-\mathrm{q}}}-1\right) G_{\mathrm{ci}-\mathrm{d}} & \left(\frac{1+Z_{\mathrm{oL}-\mathrm{q}} Y_{\mathrm{o}-\infty-\mathrm{q}}}{1+Z_{\mathrm{oL}-\mathrm{q}} Y_{\mathrm{o}-\mathrm{q}}}+\frac{1+Z_{\mathrm{oL}-\mathrm{d}} Y_{\mathrm{o}-\infty-\mathrm{qd}}}{1+Z_{\mathrm{oL}-\mathrm{d}} Y_{\mathrm{o}-\mathrm{d}}}-1\right) \mathrm{G}_{\mathrm{ci}-\mathrm{q}} \\
0 & 0
\end{array}\right]
$$


where

$$
\mathbf{Y}_{\mathrm{o}-\infty}=\left[\begin{array}{cc}
Y_{\mathrm{o}-\infty-\mathrm{d}} & Y_{\mathrm{o}-\infty-\mathrm{qd}} \\
Y_{\mathrm{o}-\infty-\mathrm{dq}} & Y_{\mathrm{o}-\infty-\mathrm{q}}
\end{array}\right]=\left[\begin{array}{cc}
Y_{\mathrm{o}-\mathrm{d}}+\frac{T_{\mathrm{oi}-\mathrm{d}} G_{\mathrm{co}-\mathrm{d}}}{G_{\mathrm{ci}-\mathrm{d}}} & Y_{\mathrm{o}-\mathrm{d}}+\frac{T_{\mathrm{oi}-\mathrm{q}} G_{\mathrm{co}-\mathrm{qd}}}{G_{\mathrm{ci}-\mathrm{d}}} \\
Y_{\mathrm{o}-\mathrm{q}}+\frac{T_{\mathrm{oi}-\mathrm{d}} G_{\mathrm{co}-\mathrm{dq}}}{G_{\mathrm{ci}-\mathrm{q}}} & Y_{\mathrm{o}-\mathrm{q}}+\frac{T_{\mathrm{oi}-q} G_{\mathrm{co}-\mathrm{q}}}{G_{\mathrm{ci}-\mathrm{q}}}
\end{array}\right]
$$

The expressions of the special parameters in Equations (40) and (42) equal the expressions defined for the corresponding DC-DC converters as explicitly given in Reference ([12], p. 356, Equation (8.2)).

\subsection{Discussions}

\subsubsection{Special Impedance-like Parameters}

The complexity to solve analytically and explicitly the load-affected transfer functions in Equation (16) (Section 2.1.2) and in Equation (36) (Section 2.2) may be understood according to the solved $\left[\mathbf{I}+\mathbf{Y}_{\mathrm{o}} \mathbf{Z}_{\mathrm{oL}}\right]^{-1}$ (cf. Equation (36)), which can be given by

$$
\frac{\left[\begin{array}{cc}
1+Y_{\mathrm{o}-\mathrm{q}} Z_{\mathrm{oL}-\mathrm{q}}+Y_{\mathrm{o}-\mathrm{dq}} Z_{\mathrm{oL}-\mathrm{qd}} & Y_{\mathrm{o}-\mathrm{d}} Z_{\mathrm{oL}-\mathrm{qd}}+Y_{\mathrm{o}-\mathrm{qd}} Z_{\mathrm{oL}-\mathrm{q}} \\
Y_{\mathrm{o}-\mathrm{q}} Z_{\mathrm{oL}-\mathrm{q}}+Y_{\mathrm{o}-\mathrm{dq}} Z_{\mathrm{oL}-\mathrm{d}} & 1+Y_{\mathrm{o}-\mathrm{d}} Z_{\mathrm{oL}-\mathrm{d}}+Y_{\mathrm{o}-\mathrm{qd}} Z_{\mathrm{oL}-\mathrm{dq}}
\end{array}\right]}{\left(1+Y_{\mathrm{o}-\mathrm{q}} Z_{\mathrm{oL}-\mathrm{q}}+Y_{\mathrm{o}-\mathrm{dq}} Z_{\mathrm{oL}-\mathrm{qd}}\right)\left(1+Y_{\mathrm{o}-\mathrm{d}} Z_{\mathrm{oL}-\mathrm{d}}+Y_{\mathrm{o}-\mathrm{qd}} Z_{\mathrm{oL}-\mathrm{dq}}\right)-\left(Y_{\mathrm{o}-\mathrm{d}} Z_{\mathrm{oL}-\mathrm{qd}}+Y_{\mathrm{o}-\mathrm{qd}} Z_{\mathrm{oL}-\mathrm{q}}\right)\left(Y_{\mathrm{o}-\mathrm{q}} Z_{\mathrm{oL}-\mathrm{q}}+Y_{\mathrm{o}-\mathrm{dq}} Z_{\mathrm{oL}-\mathrm{d}}\right)}
$$

It may be also obvious that the full-order special impedance parameters cannot be found in analytical form, because the required EET-method-like formulations (cf. Section 1, Equation 1) cannot be found.

All the ideal impedance-like special parameters given in Equations (13), (22), (33), and (42) are invariant to the feedback and feedforward schemes applied in the converter and to the type of load connected at the output terminal of the converter [12]. Consequently, the ideal parameters can be computed by means of the open-loop transfer functions. The other special parameters given in Equations (11), (20), (31), and (40) are invariant to those feedback arrangements, which are taken from the opposite terminal, where the parameters are assumed to be measured. They will change if the feedback is taken from the same terminal, where the parameters are assumed to be measured. This information dictates the way to compute the special parameters based on the corresponding open or closed-loop transfer functions.

\subsubsection{Stability Assessment}

The stability of the cascaded system comprising of the converter and its source or load subsystem can be assessed by the means of the multivariable impedance-based sensitivity functions $\left[\mathbf{I}+\mathbf{Z}_{\mathrm{x}} \mathbf{Y}_{\mathrm{y}}\right]^{-1}$ or $\left[\mathbf{I}+\mathbf{Y}_{\mathrm{y}} \mathbf{Z}_{\mathrm{x}}\right]^{-1}$, where the impedance and admittance matrixes comprise of the impedances and admittances related to the interface between the converter and its subsystem, by applying generalized Nyquist stability criterion $[27,28]$. The stability can be assessed by computing the determinant of $\left[\mathbf{I}+\mathbf{Z}_{\mathrm{x}} \mathbf{Y}_{\mathrm{y}}\right]$ or $\left[\mathbf{I}+\mathbf{Y}_{\mathrm{y}} \mathbf{Z}_{\mathrm{x}}\right]$ (i.e., the impedance-ratio-based multivariable characteristic polynomial) in a similar manner as in a single-input-single-output (SISO) system by applying the basic Nyquist stability criterion [13] but the critical point will be the origin $(0,0)$ of the complex plane instead of $(-1,0)$. The form of the determinant is explicitly given in Equation (43) as its denominator. If the interface, at which the stability is to be assessed, is of SISO type as in the source-side interfaces in the above treated inverters in Sections 2.1.1 and 2.2.1 then the relevant impedance ratio comprises of the input and output impedances of the subsystems as shown in Equations (8) and (28). In this case, the basic Nyquist stability criterion can be applied to the corresponding impedance ratio in terms of the critical point $(-1,0)$, respectively.

If the grid is symmetrically loaded then $Z_{d}\left(Y_{d}\right)$ equals $Z_{q}\left(Y_{q}\right)$ and $Z_{q d}\left(Y_{q d}\right)$ equals $-Z_{d q}\left(Y_{d q}\right)$. Theoretically, the same equalities may be valid also in the inverter. As a consequence, $\left[\mathbf{I}+\mathbf{Z}_{\mathrm{x}} \mathbf{Y}_{\mathrm{y}}\right]^{-1}$ equals $\left[\mathbf{I}+\mathbf{Y}_{\mathrm{y}} \mathbf{Z}_{\mathrm{x}}\right]^{-1}$ and the stability can be assessed based on either of these sensitivity functions. In practice, the equalities may not be, however, valid. 
As discussed in Section 1, the robust performance (i.e., sufficient phase (PM) and gain (GM) margins for not affecting significantly the original transfer functions via the peaking in the corresponding impedance-based sensitivity function [10]) can be given in terms of a specific forbidden region as given in Figure 1 (Section 1) in SISO-type interface. The least space requiring forbidden regions in Figure 1 is the MPC region, where the radius of circle equals the inverse of the maximum allowed peaking $(\mathrm{M})$ in the sensitivity function (S). denoted by $\mathrm{M}$. The maximum peaking can be given in terms of PM and GM according to ([14], pp. 92, 93) as

$$
\mathrm{M}_{\mathrm{PM}}=\frac{1}{2 \sin (\mathrm{PM} / 2)} \mathrm{M}_{\mathrm{GM}}=\frac{\mathrm{GM}}{\mathrm{GM}-1}
$$

The MPC-forbidden region takes into account the combined peaking effect of PM and GM. In case of the DC-interfaced inverters, the DC-interface-related robust performance can be obtained by requiring the contour of the impedance-based minor-loop gain to stay out of the MPC-defined forbidden region as stated in Reference [10]. In this case, the impedance-based minor-loop gain is the same for all the source-affected transfer functions, and the maximum peaking can be explicitly defined by means of the PM and GM associated to the minor-loop gain.

In the general case, when the sensitivity function is also a multivariable function as in Equation (43), the load/source-affected transfer functions are composed of two or more elements having each a different impedance-based sensitivity function. Equation (43) is presented in Equation (45) in a more convenient form, and the load-affected $\mathrm{G}_{\mathrm{co}}^{\mathrm{L}}$ in Equation (36) applying Equation (45) is presented in its explicit form in Equation (46), respectively. Equation (46) shows explicitly the subcomponents of each load-affected elements of $\mathbf{G}_{\mathrm{co}}^{\mathrm{L}}$. If the same procedures are applied for $\mathbf{Z}_{\mathrm{in}}^{\mathrm{L}}$ and $\mathbf{G}_{\mathrm{ci}}^{\mathrm{L}}$ in Equation (36) then the number of subcomponents is higher than two, which will increase the complexity of the corresponding transfer functions significantly. Equation (45) indicates that we can find four different impedance-based sensitivity functions $\left(S_{i}\right)$ as given in Equation (47), which may exhibit different peaking behavior, because the numerator of the sensitivity functions contains one common factor with the denominator.

$$
\begin{aligned}
& \frac{\left[\begin{array}{cc}
1+a & b \\
c & 1+d
\end{array}\right]}{(1+a)(1+b)-b c} \\
& \mathbf{G}_{\mathrm{co}}^{\mathrm{L}}=\left[\begin{array}{cc}
G_{\mathrm{co}-\mathrm{d}}^{\mathrm{L}} & G_{\mathrm{co}-\mathrm{qd}}^{\mathrm{L}} \\
G_{\mathrm{co}-\mathrm{dq}}^{\mathrm{L}} & G_{\mathrm{co}-\mathrm{q}}^{\mathrm{L}}
\end{array}\right]=\frac{\left[\begin{array}{cc}
(1+\mathrm{a}) G_{\mathrm{co}-\mathrm{d}}+\mathrm{cG}_{\mathrm{co}-\mathrm{dq}} & (1+\mathrm{a}) G_{\mathrm{co}-\mathrm{qd}}+\mathrm{c} G_{\mathrm{co}-\mathrm{q}} \\
(1+\mathrm{d}) G_{\mathrm{co}-\mathrm{dq}}+\mathrm{b} G_{\mathrm{co}-\mathrm{d}} & (1+\mathrm{d}) G_{\mathrm{co}-\mathrm{q}}+\mathrm{b} G_{\mathrm{co}-\mathrm{qd}}
\end{array}\right]}{(1+\mathrm{a})(1+\mathrm{d})-\mathrm{bc}} \\
& S_{1}=\frac{1+\mathrm{a}}{(1+\mathrm{a})(1+\mathrm{d})-\mathrm{bc}} \quad S_{2}=\frac{\mathrm{b}}{(1+\mathrm{a})(1+\mathrm{d})-\mathrm{bc}} \quad S_{3}=\frac{\mathrm{c}}{(1+\mathrm{a})(1+\mathrm{d})-\mathrm{bc}} \quad S_{4}=\frac{1+\mathrm{d}}{(1+\mathrm{a})(1+\mathrm{d})-\mathrm{bc}}
\end{aligned}
$$

If the cross-coupling terms are small as assumed in Section 2.2.2 then we have two different sensitivity functions as given in Equation (37). In this specific case, the stability of the system can be inferred by requiring that both of the impedance-ratio-based minor-loop gains satisfy Nyquist stability criterion [13]. In addition, the robust stability can be ensured by applying the MPC-based criteria to both of the minor-loop gains [10]. In general, it is not recommended to neglect the cross-coupling terms, because they may have significant impact on the validity of the stability information as discussed in References [78-82]. The complexity of the analysis with all the cross-coupling terms included is usually the reason for neglecting the cross-couplings [83-85].

In general case, the formulation for the requirements for the robust stability (RS) has to be performed based on the maximum singular value $(\bar{\sigma})$ of the multivariable sensitivity function $\mathbf{S}$, which equals $\left[\mathbf{I}+\mathbf{Y}_{\mathrm{y}} \mathbf{Z}_{\mathrm{x}}\right]^{-1}$ or $\left[\mathbf{I}+\mathbf{Z}_{\mathrm{x}} \mathbf{Y}_{\mathrm{y}}\right]^{-1}[14,15]$, and which can be easily computed by applying Matlab ${ }^{\mathrm{TM}}$ command svd (S) (i.e., singular value decomposition). In case of full-matrix uncertainty as in this case, RS is guaranteed when $\bar{\sigma}<1$ [14]. 


\subsubsection{General Load}

Figure 12 shows the multivariable equivalent circuits of the inverter output in grid-forming mode, and the power grid in multivariable mode. The source effect caused by the inverter (i.e., $\mathbf{Z}_{\text {inv }}$ ) in the general-load case can be computed in a similar manner as performed in Section 2.1.1, which yields

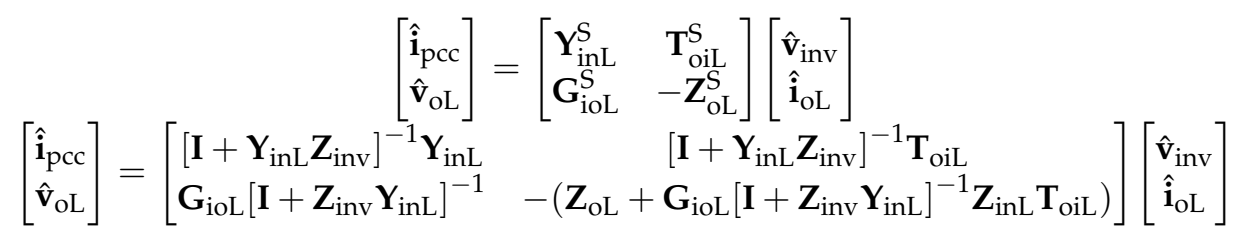

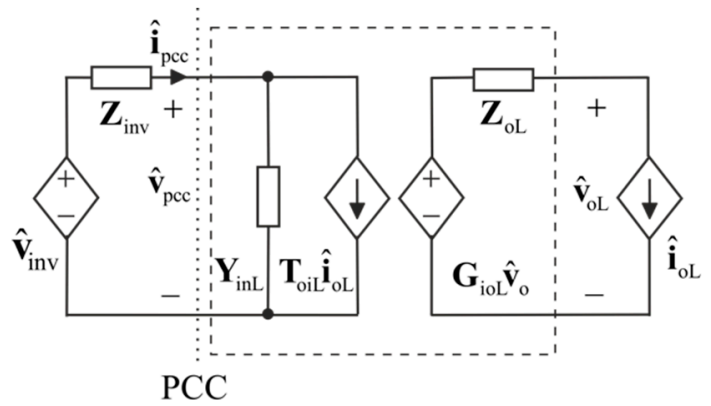

Figure 12. The equivalent circuits of the inverter output and the generalized power grid in grid-forming mode of operation.

Equation (48) shows that the stability of the interface can be assessed based on the output impedance of the inverter $\left(\mathbf{Z}_{\text {inv }}\right)$ and the input admittance of the grid $\left(\mathbf{Y}_{\mathrm{inL}}\right)$ by applying General Nyquist stability criterion to $\left[\mathbf{I}+\mathbf{Y}_{\text {inL }} \mathbf{Z}_{\text {inv }}\right]^{-1}$ and $\left[\mathbf{I}+\mathbf{Y}_{\mathrm{o}} \mathbf{Z}_{\mathrm{inL}}\right]^{-1}$ as stated also in Section 2.1.2. The other properties of the cascaded system cannot be computed even if the voltage (cf. Equation (49)) and current (cf. Equation (48)) of PCC can be explicitly measured, because $\mathbf{T}_{\mathrm{oiL}}$ cannot be measured in practice.

$$
\hat{\mathbf{v}}_{\text {pcc }}=\left[\mathbf{I}+\mathbf{Z}_{\text {inv }} \mathbf{Y}_{\text {inL }}\right]^{-1} \hat{\mathbf{v}}_{\text {inv }}-\left[\mathbf{I}+\mathbf{Z}_{\text {inv }} \mathbf{Y}_{\text {inL }}\right]^{-1} \mathbf{Z}_{\text {inv }} \mathbf{T}_{\text {oiL }} \hat{\mathbf{i}}_{\text {oL }}
$$

Figure 13 shows the multivariable equivalent circuits of the inverter output in grid-feeding mode, and the power grid in multivariable mode. The source effect caused by the inverter $\left(\mathbf{Y}_{\text {inv }}\right)$ in the general-load case can be computed in a similar manner as performed in Section 2.2.1, which yields

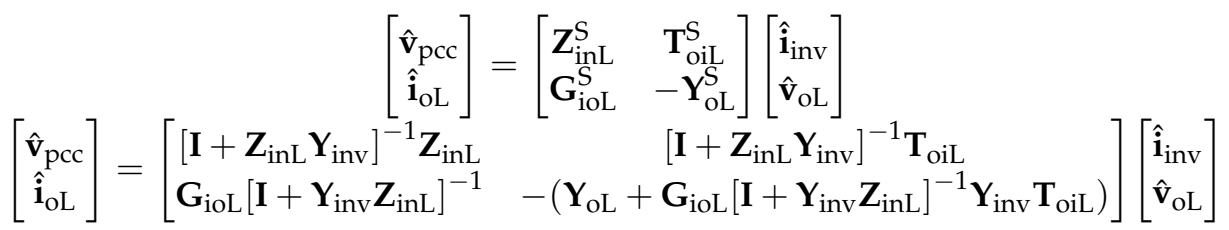

Equation (50) shows that the stability of the interface can be assessed based on the output admittance of the inverter $\left(\mathbf{Y}_{\text {inv }}\right)$ and the input impedance of the grid $\left(\mathbf{Z}_{\text {inL }}\right)$ by applying Nyquist Generalized stability criterion to $\left[\mathbf{I}+\mathbf{Z}_{\text {inL }} \mathbf{Y}_{\text {inv }}\right]^{-1}$ and $\left[\mathbf{I}+\mathbf{Y}_{\text {inv }} \mathbf{Z}_{\text {inL }}\right]^{-1}$ as stated also in Section 2.2.2. In grid-feeding mode, the inverter synchronizes the voltage (cf. Equation (51) and current (cf. Equation (50) of the PCC interface. The load system can be assumed to be such that the elements of the system are basically invariant to each other. Therefore, $\mathrm{G}_{\mathrm{ioL}}$ and $\mathbf{T}_{\mathrm{oiL}}$ are equal as the circuit-theoretical reciprocity theorem implies as well [86]. The voltage (cf. Equation (50)) and current (cf. Equation (51)) of the PCC interface (cf. Figure 13)

$$
\hat{\mathbf{i}}_{\text {pcc }}=\left[\mathbf{I}+\mathbf{Y}_{\text {inv }} \mathbf{Z}_{\text {inL }}\right]^{-1} \hat{\mathbf{i}}_{\text {inv }}-\left[\mathbf{I}+\mathbf{Y}_{\text {inv }} \mathbf{Z}_{\text {inL }}\right]^{-1} \mathbf{Y}_{\text {inv }} \mathbf{T}_{\text {oiL }} \hat{\mathbf{v}}_{\text {oL }}
$$


Similarly, as in case of grid-forming-mode operation, the phase of $\mathbf{i}_{\mathrm{oL}}$ cannot be determined based on the available information, because $\mathbf{T}_{\mathrm{oiL}}$ cannot be measured in practice. This means that the synchronizing angle cannot be corrected to produce real power at certain point in the grid system without external knowledge on the phase behavior from the grid coordinated control facilities.

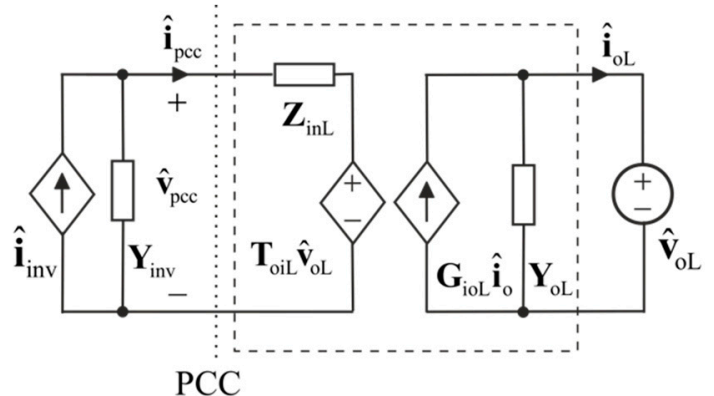

Figure 13. The equivalent circuits of the inverter output and the generalized power grid in grid-feeding mode of operation.

\section{Experimental Evidence}

The grid-forming-mode inverter, which is reported more in detail in Reference [26], is evaluated by applying Typhoon HIL real-time simulation setup, Boombox control platform, and Venable frequency response analyzer as shown in Figure 14.

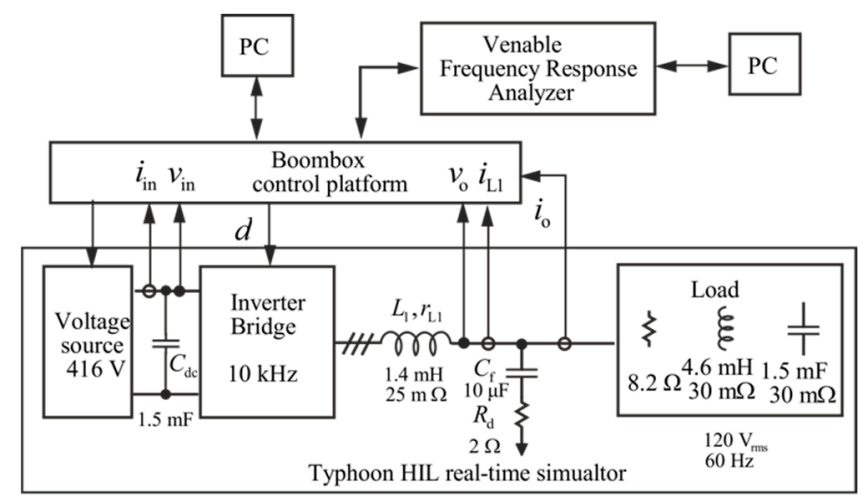

Figure 14. Grid-forming-mode inverter test setup.

The grid-feeding-mode inverter, which is reported more in detail Reference [87], is evaluated by using the real hardware setup as shown in Figure 15, where the PV (PVS7000) and grid (PAS15000) emulators are manufactured by Spitzenberger \& Spies as well as the inverter is based on MyWay platform (MWINV-1044-SIC). The given frequency responses are measured applying the MIMO measurement technique reported in Reference [80], and the perturbation signals are injected via the grid emulator in dq domain.

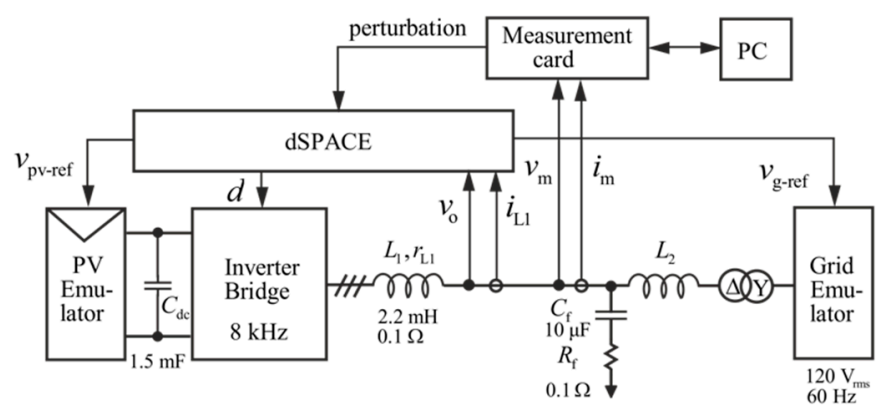

Figure 15. Grid-feeding-mode inverter test setup. 


\subsection{Grid-Forming-Mode Inverter}

The inductor-current and output-voltage loop gains are given in Figures 16 and 17, where the effects of the different loads are visible: The unterminated (i.e., loaded by constant-current sink) loop gain is denoted by red color, the resistor-loaded loop gain by blue color, and the parallel-connected resistor-inductor-capacitor (RLC) loaded loop gain by black color, respectively. The unterminated loop (red) gain indicates unstable operation having the crossover frequency at $20 \mathrm{~Hz}$. The resistor and RLC loading increases the crossover frequency to $300 \mathrm{~Hz}$ and they stabilize the converter as well. Figure 17 shows that the system is stable, when the output-voltage loop is properly tuned: Stabilization of the inverter requires that the voltage-loop crossover frequency is placed at higher frequency than the unstable pole of the system (cf. Figure 16 (red) vs. Figure 17 (red)).
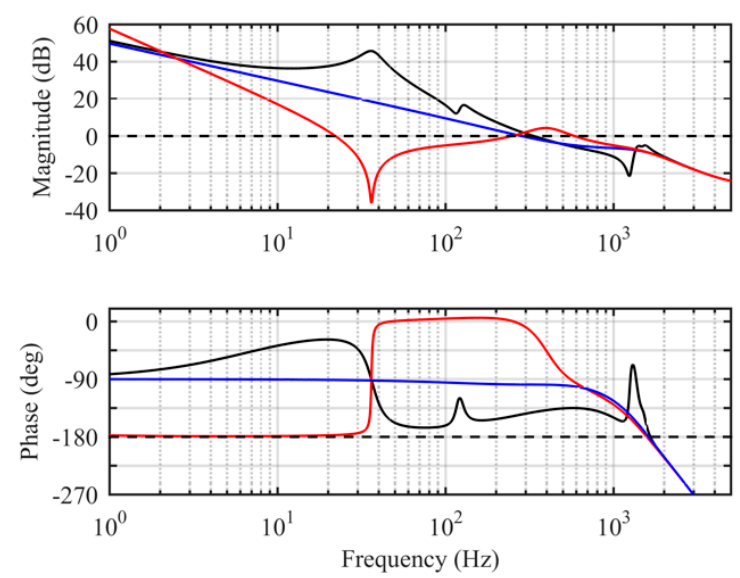

Figure 16. The inductor-current loop gain at unterminated mode (red), as resistor loaded (blue), and as parallel RLC loaded (black).
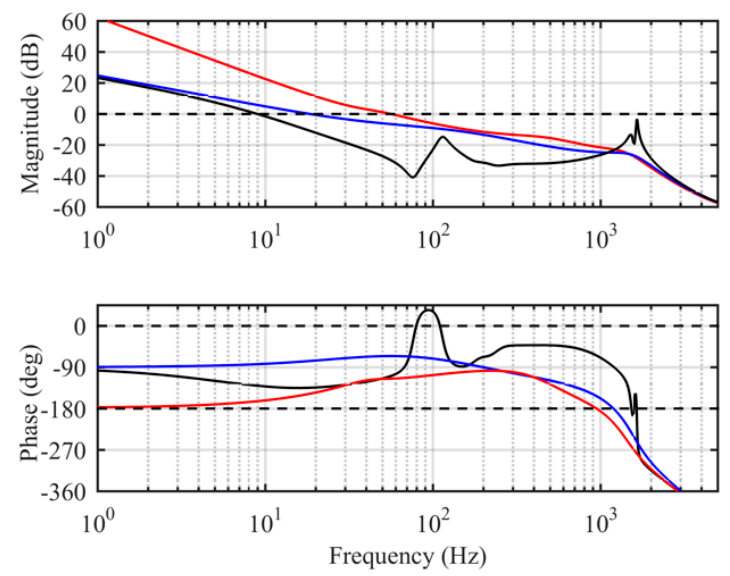

Figure 17. The output-voltage loop gain at unterminated mode (red), as resistor loaded (blue), and as parallel RLC loaded (black).

It may be obvious that the load impedance has significant effect on the converter dynamic behavior, which is actually the consequence of the rather high magnitudes of the output impedance as shown in Figure 18. The high-output impedance may be reduced by applying output current feedforward.

Figure 18 shows that the output impedance of the grid-forming inverter exhibits such symmetry that $Z_{\mathrm{o}-\mathrm{d}}=Z_{\mathrm{o}-\mathrm{q}}$ and $Z_{\mathrm{o}-\mathrm{dq}}=-Z_{\mathrm{o}-\mathrm{qd}}$ as discussed also in case of the grid impedance in Section 2.3.2. If the grid is asymmetrically loaded, then its impedance (admittance) may not have this property. It this property exists in inverter and grid then the two multivariable sensitivity functions will be identical. 

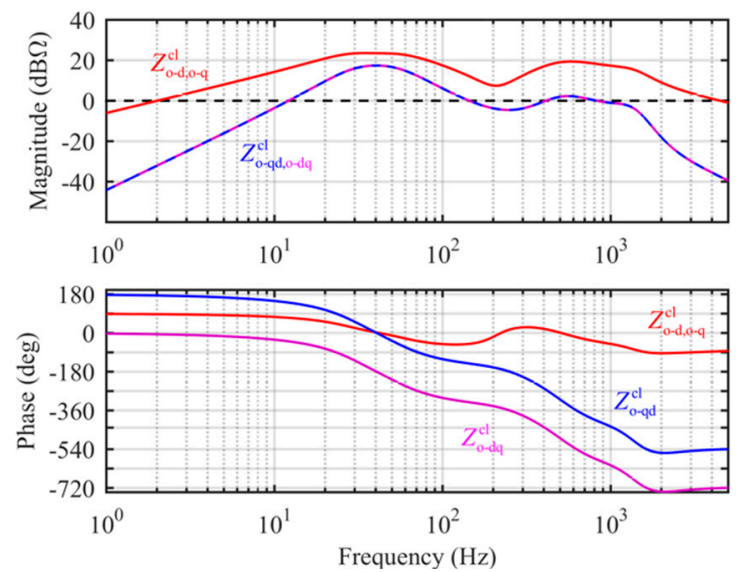

Figure 18. The measured closed-loop output impedances of the grid-forming inverter, where the red color denotes the closed-loop $Z_{\mathrm{o}-\mathrm{d}}$ and $Z_{\mathrm{o}-\mathrm{q}}$, the blue color denotes $Z_{\mathrm{o}-\mathrm{qd}}$, and the magenta color $\mathrm{Z}_{\mathrm{O}-\mathrm{dq}}$, respectively.

Figure 19 shows the measured (black) and predicted (red and blue) closed-loop input impedance of the grid-forming inverter, when the inverter is loaded with the parallel-connected RLC circuit (cf. Figure 14). The blue-colored input impedance denotes the case, where the analytical model includes all the output-terminal-side cross-couplings. The red-colored input impedance denotes the case, where the cross-couplings are omitted (cf. Equation (19), Section 2.1.2). According to Figure 19, the cross-couplings do not have significant contribution on the behavior of the load-affected input impedance. This phenomenon cannot be generalized, because the grid impedance may not exhibit similar symmetry in practice as in this special case.
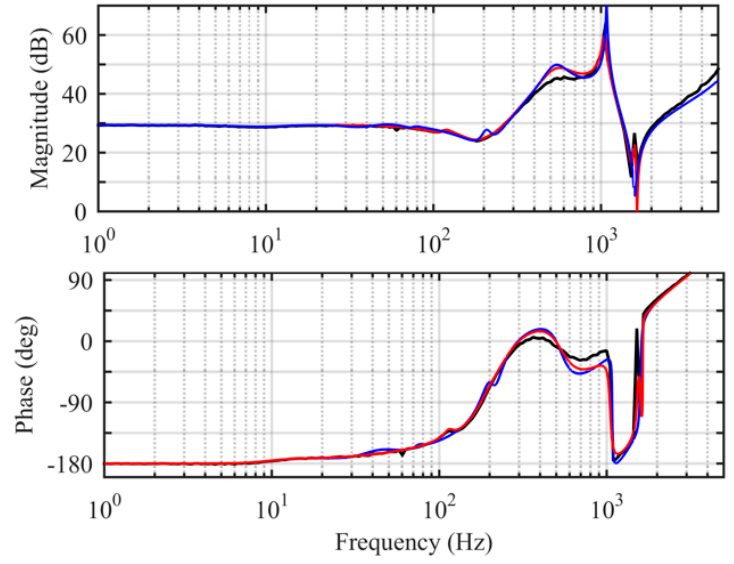

Figure 19. The RLC-load-affected input impedance of the grid-forming inverter, where the black color denotes the measured input impedance, the red color denotes the predicted input impedance with all the cross-couplings, and the blue color denotes the predicted input impedance omitting all the cross-couplings.

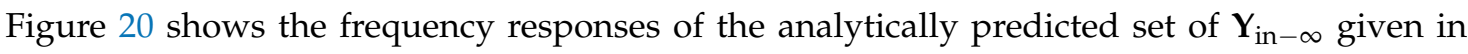
Equation (13) (cf. Section 2.1.1). According to Reference [12], the low-frequency behavior of the closed-loop input admittance is dominated by the ideal input admittance, which in this case equals the d-component of $\mathbf{Y}_{\mathrm{in}-\infty}$ (cf. black line in Figure 20) having the value of approximately $-30 \mathrm{~dB} \Omega^{-1}$ at the low frequencies. As an impedance, this value equals $30 \mathrm{~dB} \Omega$, respectively. Figure 19 shows the closed-loop input impedance of the inverter, where the low-frequency value equals approximately

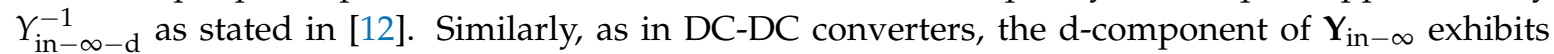
negative-incremental admittance behavior as well. 

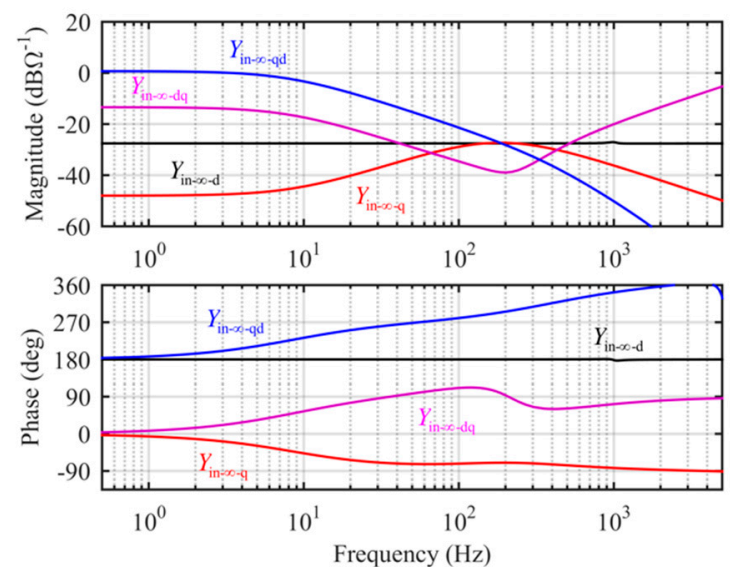

Figure 20. The set of predicted frequency responses of the multi-variable ideal input admittance $\mathbf{Y}_{\text {in }-\infty}$ computed according to Equation (13) in Section 2.1.1.

\subsection{Grid-Feeding-Mode Inverter}

The stability of the grid-feeding-mode inverter is evaluated by computing the eigenvalues of the multivariable impedance-based minor-loop gain (i.e., $\mathbf{Y}_{\text {inv-o }} \mathbf{Z}_{\text {grid-in }}$ ) and the Nyqyist plot of $\operatorname{det}\left[\mathbf{I}+\mathbf{Y}_{\text {inv-o }} \mathbf{X}_{\text {grid-in }}\right]$ as well as by computing the maximum singular value of the sensitivity function $\mathbf{S}=\left[\mathbf{I}+\mathbf{Y}_{\text {inv-o }} \mathbf{X}_{\text {grid-in }}\right]^{-1}$. The information given by the above-named impedance-based elements is validated by measuring the frequency response of the inductor-current loop as well as the time-domain behavior of the q component of the output current. The value of the series inductor $L_{2}$ (cf. Figure 15) is varied from $0 \mathrm{mH}$ to $12 \mathrm{mH}$, respectively.

\subsubsection{Impedance-Ratio-Based Analysis}

Figure 21 shows the plots of the maximum singular value of $\mathbf{S}=\left[\mathbf{I}+\mathbf{Y}_{\text {inv-o }} \mathbf{X}_{\text {grid-in }}\right]^{-1}$ in respect to the frequency, when $L_{2}$ equals 0 and $12 \mathrm{mH}$, respectively. The red line shows that the robustness of stability is poor (i.e., $\bar{\sigma}>1$ ) at the low frequencies up to $60 \mathrm{~Hz}$ and when the frequency exceeds $1 \mathrm{kHz}$.

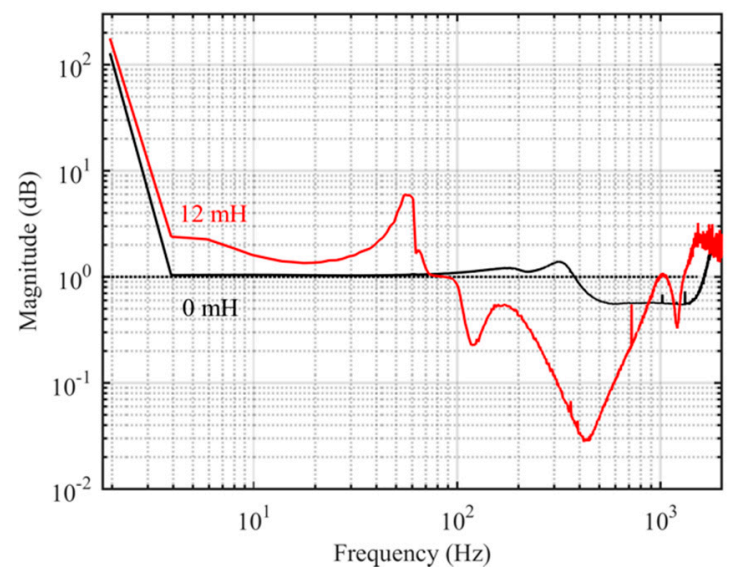

Figure 21. The maximum singular value of the multivariable impedance-based sensitivity function, where the black line denotes the singular value computed when $L_{2}$ equals $0 \mathrm{mH}$ and the red line denotes the case when $L_{2}$ equals $12 \mathrm{mH}$.

Figure 22 shows the Bode plots of the eigenvalues of the multivariable impedance-based minor-loop gain (i.e., $\mathbf{Y}_{\text {inv-o }} \mathbf{X}_{\text {grid-in }}$ ) when $L_{2}$ equals $12 \mathrm{mH}$. The dashed lines denote the eigenvalues, when the cross-couplings are omitted. The dashed-line circles are placed at the frequencies, which indicate poor robustness of stability or unstable operation. The frequency response of $\lambda_{1}$ 
(red color) indicates that the phase margin is very low at the low frequencies, and the system is unstable approximately at $800 \mathrm{~Hz}$ (i.e., the derivative of the phase is negative, when crossing the \pm 180 -degree line) [88]. The frequency response of $\lambda_{2}$ implies that the system is unstable approximately at $100 \mathrm{~Hz}$ and $1 \mathrm{kHz}$ [89].
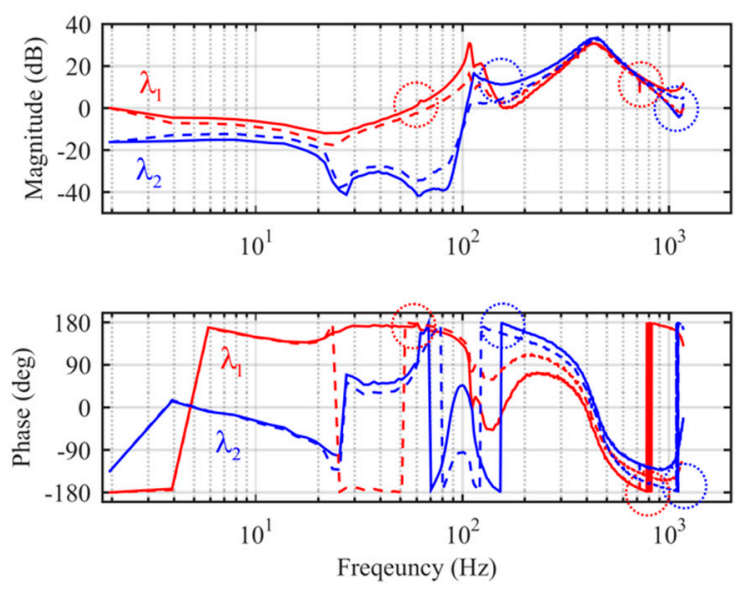

Figure 22. The Bode plots of the eigenvalues $\lambda_{1}$ (red) and $\lambda_{2}$ (blue), where the dashed lines denote the case having the cross-couplings omitted. The dashed-line circles denote the frequencies, where the stability of the system is questionable $\left(L_{2}=12 \mathrm{mH}\right)$.

Figure 23a shows the full Nyquist plot of $\lambda_{1}$, and Figure 23b shows the extended view of the plot in the vicinity of the critical point $(-1,0)$. Figure $23 \mathrm{~b}$ shows that the system is stable but the phase margin is very small.

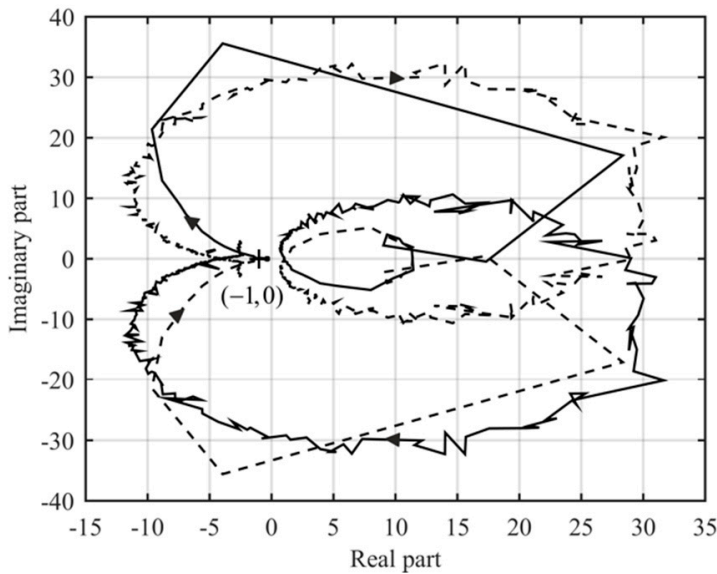

(a)

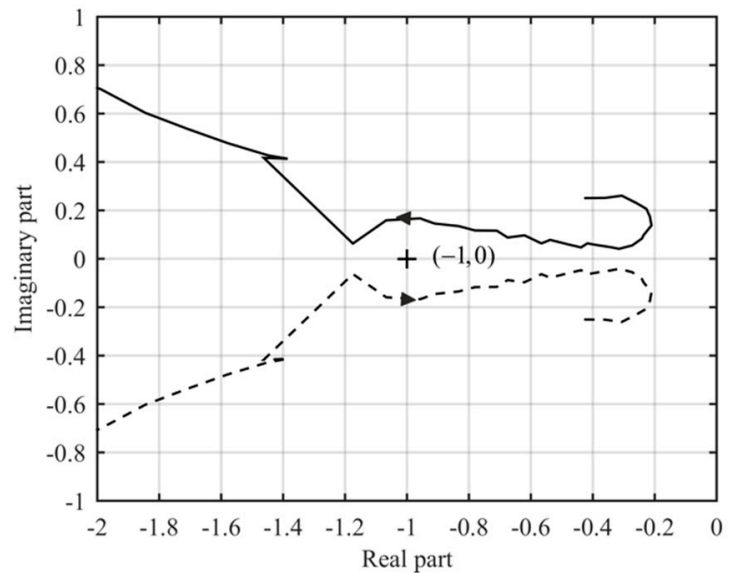

(b)

Figure 23. The Nyquist plot of $\lambda_{1}$ : (a) the full plot, and (b) the extended plot in the vicinity of the point $(-1,0)\left(L_{2}=12 \mathrm{mH}\right)$. The solid line denotes contour for positive frequencies and the dashed line denotes the contour for negative frequencies. The arrowhead of the solid line shows the direction of increasing frequencies, respectively.

Figure 24a shows the full Nyquist plot of $\lambda_{2}$, and Figure 24b shows the extended view of the plot in the vicinity of the critical point $(-1,0)$. Figure $24 \mathrm{~b}$ implies that the system is unstable. 


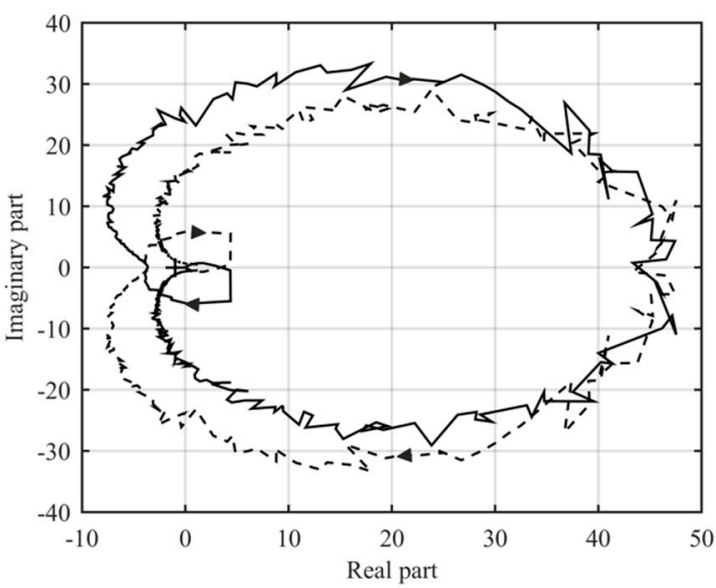

(a)

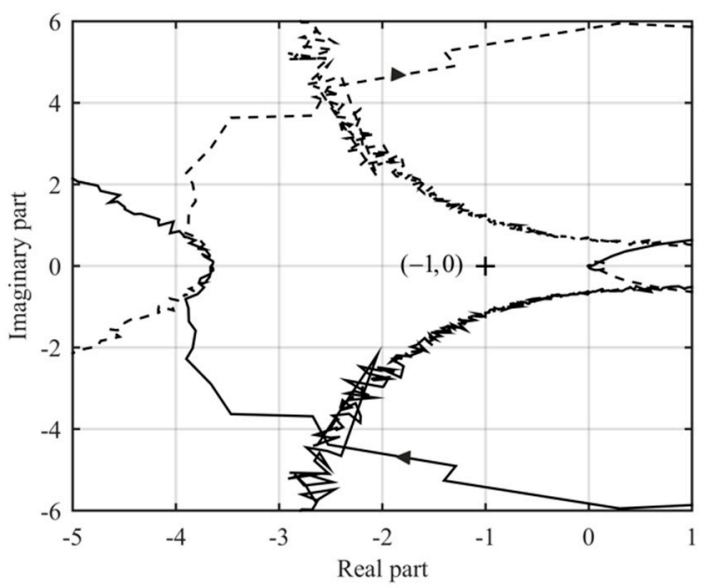

(b)

Figure 24. The Nyquist plot of $\lambda_{2}$ : (a) the full plot, and (b) the extended plot in the vicinity of the critical point $(-1,0)\left(L_{2}=12 \mathrm{mH}\right)$ (cf. the caption of Figure 23 for the explicit definitions of the other contents in the figure).

Figure 25 shows the Bode plot of $\operatorname{det}\left[\mathbf{I}+\mathbf{Y}_{\text {inv-o }} \mathbf{X}_{\text {grid }}\right]$, when $L_{2}$ equals 0,7 , and $12 \mathrm{mH}$, where the dashed lines indicate the frequency responses, from which the cross-couplings are omitted. The full-order and reduced-order responses are quite equal at the frequencies higher than $300 \mathrm{~Hz}$ but deviate from each other significantly at the frequencies in the range from $50 \mathrm{~Hz}$ to $300 \mathrm{~Hz}$, respectively. Extracting stability information from Figure 25 is not similarly straightforward as from Figure 22.
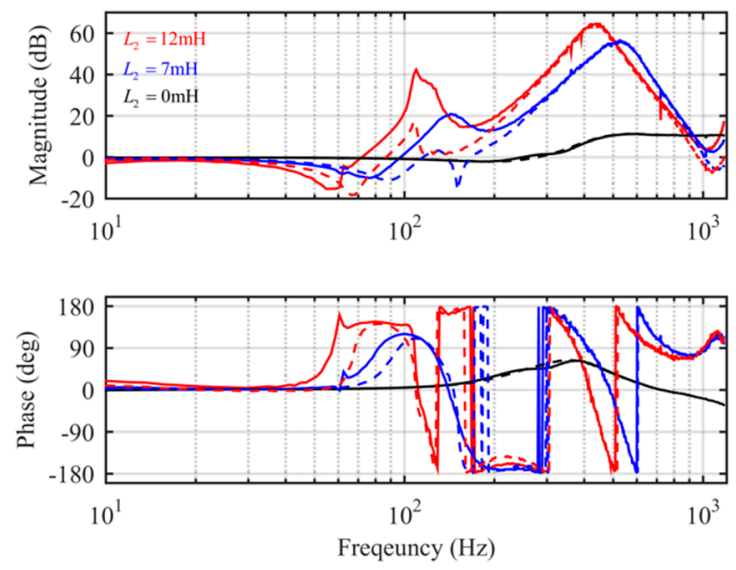

Figure 25. The frequency responses of $\operatorname{det}\left[\mathbf{I}+\mathbf{Y}_{\text {inv-o }} \mathbf{X}_{\text {grid }}\right]$, when $L_{2}$ equals 0,7 , and $12 \mathrm{mH}$. The solid lines denote the full-order responses, and the dashed lines denote the reduced-order responses, respectively.

Figure 26a shows the full-order Nyquist plot of $\operatorname{det}\left[\mathbf{I}+\mathbf{Y}_{\text {inv-o }} \mathbf{X}_{\text {grid }}\right]$, and Figure $26 \mathrm{~b}$ shows the extended plot in the vicinity of the critical point $(0,0)$, when $L_{2}$ equals $12 \mathrm{mH}$. The solid line denotes the Nyquist contour for positive frequencies and the dashed line denotes the contour for negative frequencies, respectively. The arrowhead of the solid line denotes the direction of increasing frequency. Figure $26 \mathrm{~b}$ indicates that the system is stable although the margins are extremely low. 


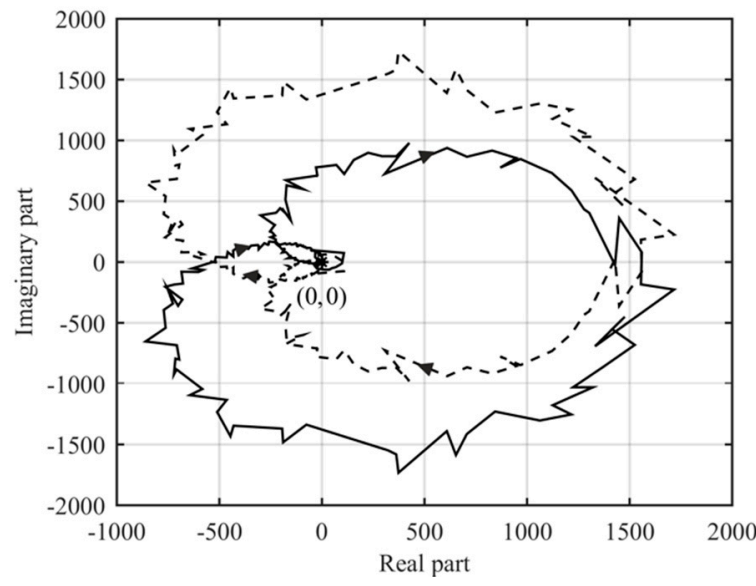

(a)

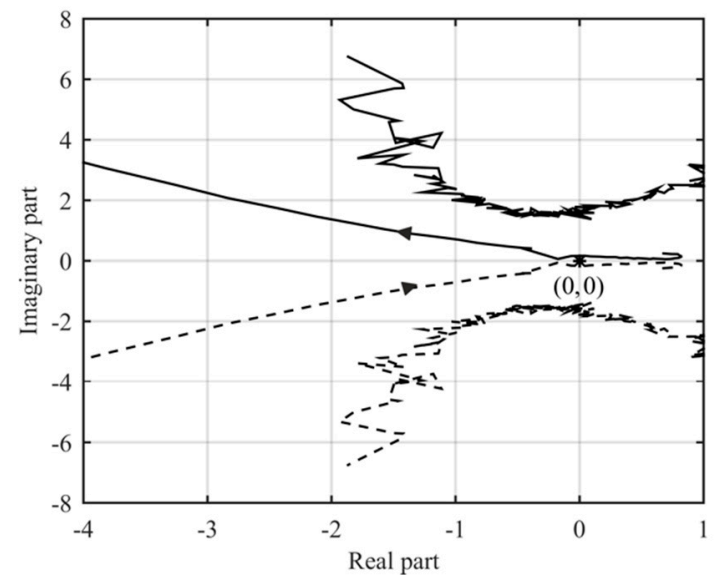

(b)

Figure 26. The Nyquist plot of $\operatorname{det}\left[\mathbf{I}+\mathbf{Y}_{\mathrm{inv}-\mathrm{o}} \mathbf{X}_{\text {grid }}\right]$ : (a) the full plot, and (b) the extended plot in the vicinity of the critical point $(0,0)\left(L_{2}=12 \mathrm{mH}\right)$ (cf. the caption of Figure 23 for the explicit definitions of the other contents in the figure).

Figure 27 shows the extended Nyquist plots of the full (red) (cf. Figure 26b) and reduced-order (blue) contours in the vicinity of the critical point $(0,0)$, when $L_{2}$ equals $12 \mathrm{mH}$. The reduced-order plot implies that the system is unstable, when encircling clockwise the critical point $(0,0)$.

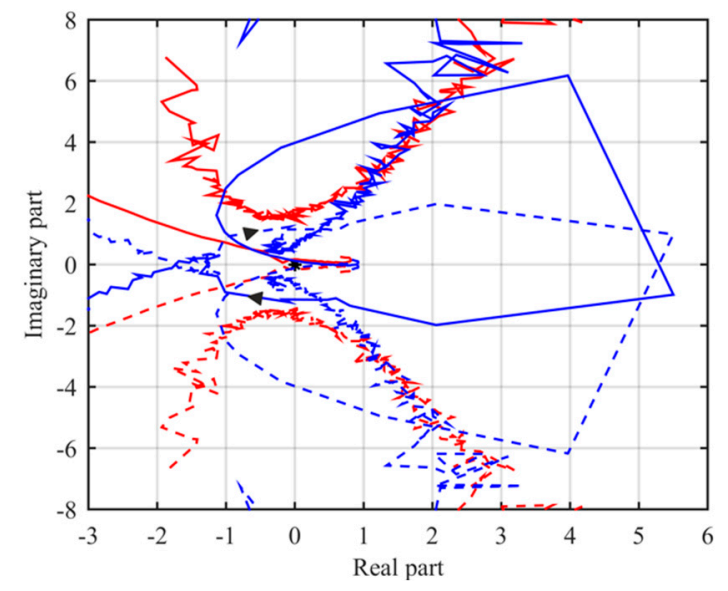

Figure 27. The extended Nyquist plots of the full (red) and reduced-order (blue) plots of $\operatorname{det}\left[\mathbf{I}+\mathbf{Y}_{\text {inv }-\mathrm{o}} \mathbf{X}_{\text {grid }}\right]$, when $L_{2}$ equals $12 \mathrm{mH}$ (cf. the caption of Figure 23 for the explicit definitions of the other contents in the figure).

The maximum singular-value plot in Figure 21 indicates that the robustness of stability is poor at the low frequencies up to $60 \mathrm{~Hz}$, and at the frequencies exceeding $1 \mathrm{kHz}$ (i.e., $\bar{\sigma}>1$ ). The eigenvalue $\lambda_{2}$ (cf. Figure 24) implied that the system is unstable. The full-order Nyquist plot of $\operatorname{det}\left[\mathbf{I}+\mathbf{Y}_{\text {inv-o }} \mathbf{X}_{\text {grid }}\right]$ (cf. Figure 26) implied that the system is stable but the stability margins would be extremely low. As discussed in Reference [14], the Nyquist plot of $\operatorname{det}\left[\mathbf{I}+\mathbf{Y}_{\text {inv-o }} \mathbf{X}_{\text {grid }}\right]$ would give the most accurate prediction on the stability. It may be also obvious that the singular value does not directly indicate that the system is unstable.

\subsubsection{Inductor-Current-Loop-Based Analysis}

Figure 28 shows the measured (solid lines) inductor-current-loop frequency responses (Figure 28a, d-component, and Figure 28b, q-component), when $L_{2}$ equals $0 \mathrm{mH}$ (blue lines) and $12 \mathrm{mH}$ (red lines). Figure 28a shows that the crossover frequency $\left(f_{\mathrm{c}}\right)$ and phase margin of the designed d-component of 
current-loop gain (blue) equal $300 \mathrm{~Hz}$ and 30 degrees, respectively. In case of weak grid (red), the grid impedance has modified the d-component of current-loop gain to have three distinct gain crossovers approximately at $90 \mathrm{~Hz}, 122 \mathrm{~Hz}$, and $143 \mathrm{~Hz}$. The corresponding phase margins vary from 28 degrees to 63 degrees, respectively, which indicates that the inverter is stable. The figure shows also that the fourth gain crossover is very close to appear approximately at $1 \mathrm{kHz}$, where the margin is only $1 \mathrm{~dB}$. The phase crossover frequency equals $1.3 \mathrm{kHz}$ with a gain margin of $4 \mathrm{~dB}$. The robustness of the stability is very poor especially in the frequency range from $20 \mathrm{~Hz}$ to $50 \mathrm{~Hz}$, where the phase margin is close to zero.
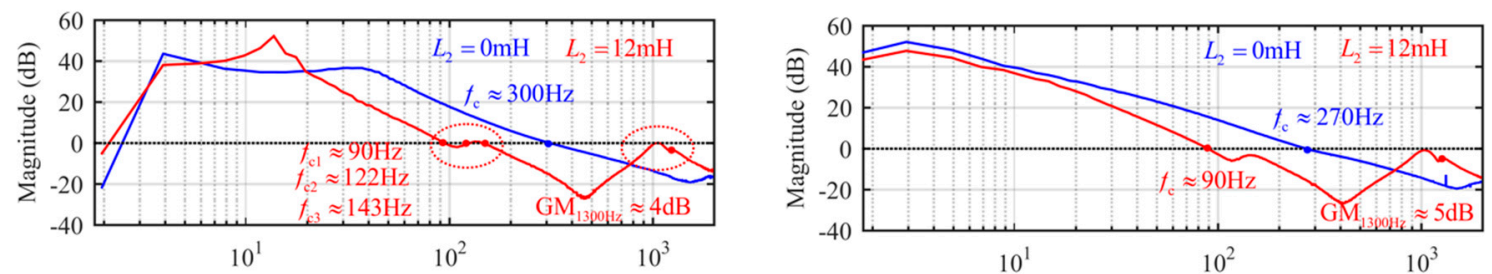

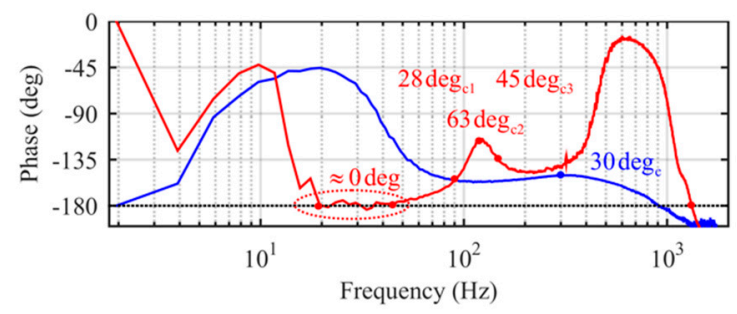

(a)

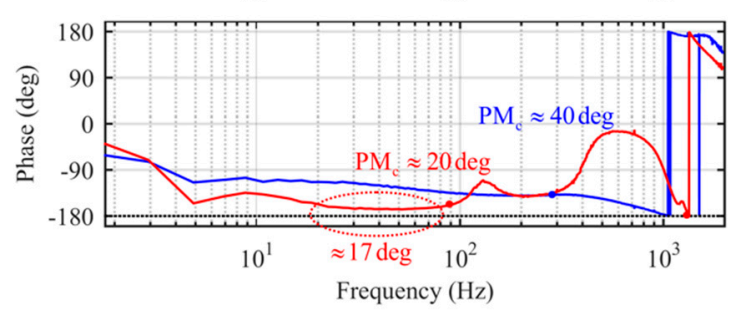

(b)

Figure 28. The measured (solid lines) current-loop gains at $L_{2}=0 \mathrm{mH}$ (blue) and $12 \mathrm{mH}$ (red): (a) d-component, and (b) q-component.

Figure $28 \mathrm{~b}$ shows that the crossover frequency $\left(f_{\mathrm{c}}\right)$ and phase margin of the designed q-component current loop (blue) equal $270 \mathrm{~Hz}$ and 40 degrees, respectively. In case of weak grid (red), the grid impedance has modified the q-component of the current-loop gain to have the crossover frequency approximately at $90 \mathrm{~Hz}$ with the phase margin of 20 degrees. As the figure shows, three other crossover frequencies are very close to appear similarly as in the d-component of the current-loop gain. The phase crossover frequency equals approximately $1.3 \mathrm{kHz}$ with the gain margin of $5 \mathrm{~dB}$. The corresponding phase margins vary from 28 degrees to 90 degrees, respectively, which indicates that the inverter is stable. The robustness of the stability is somewhat better than that of the d-component in the frequency range from $20 \mathrm{~Hz}$ to $50 \mathrm{~Hz}$, where the phase margin is close to 17 degrees instead of close to zero. The stability information given by Figure 28 may not be absolutely true, because the cross-coupling terms will contribute also to the stability information.

Figure 29 shows the measured Nyquist plot of $\operatorname{det}\left[\mathbf{I}+\mathbf{L}_{\mathbf{C}}\right]$ with cross-couplings (blue) and without cross-couplings (red), where $\mathbf{L}_{C}$ denotes the multivariable inductor-current feedback loop. The blue-colored Nyquist plot shows that the inverter is stable (i.e., no clockwise encirclement around the critical point $(0,0))$ but the margins would be low. The red-colored Nyquist plot implies that the inverter is unstable. Figures $26 \mathrm{~b}$ and 27 (Section 3.2.1) give quite the same information on the state of stability.

Figure 30 shows the Nyquist plots of the eigenvalues $\lambda_{1}$ (red) and $\lambda_{2}$ (blue), where Figure 30a shows the whole plots, and Figure 30b, the extended part of the plots in the vicinity of the critical point $(-1,0)$. The plot of $\lambda_{2}$ implies that the system is unstable.

Figure 31 shows the plot of the maximum singular value of the sensitivity function $\mathbf{S}_{\mathrm{c}}=\left[\mathbf{I}+\mathbf{L}_{\mathrm{c}}\right]^{-1}$ at $L_{2}=0$ (black), and $L_{2}=12 \mathrm{mH}$ (red), respectively. The black-line response indicates that the phase margins of the original design are rather low (cf. Figure 28) and therefore, the original design is not robustly stable. The red-line responses indicate that the robustness of stability is lost at the frequencies from $50 \mathrm{~Hz}$ to $500 \mathrm{~Hz}$ as well as at the frequencies higher than $1 \mathrm{kHz}$. 


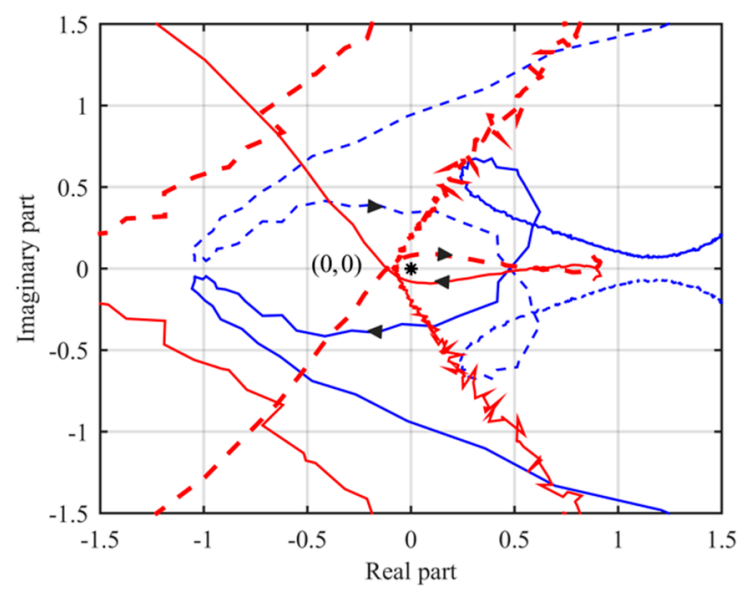

Figure 29. Nyquist plots of $\operatorname{det}\left[\mathbf{I}+\mathbf{L}_{\mathbf{C}}\right]$ with cross-couplings (blue line) and without cross-couplings (red line).
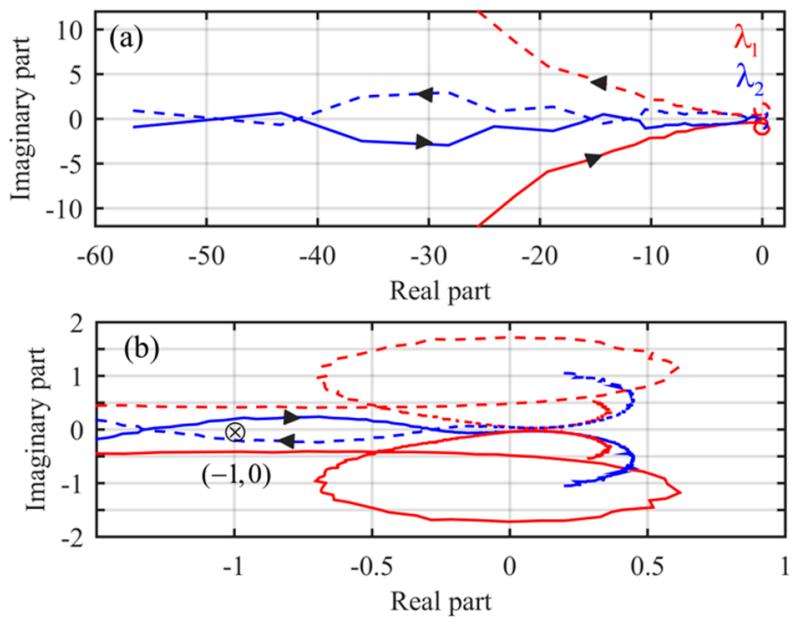

Figure 30. Nyquist plots of the current-loop-gain eigenvalues $\lambda_{1}$ (red) and $\lambda_{2}$ : (a) full plots, and (b) extended plots in the vicinity of the critical point $(-1,0)$.

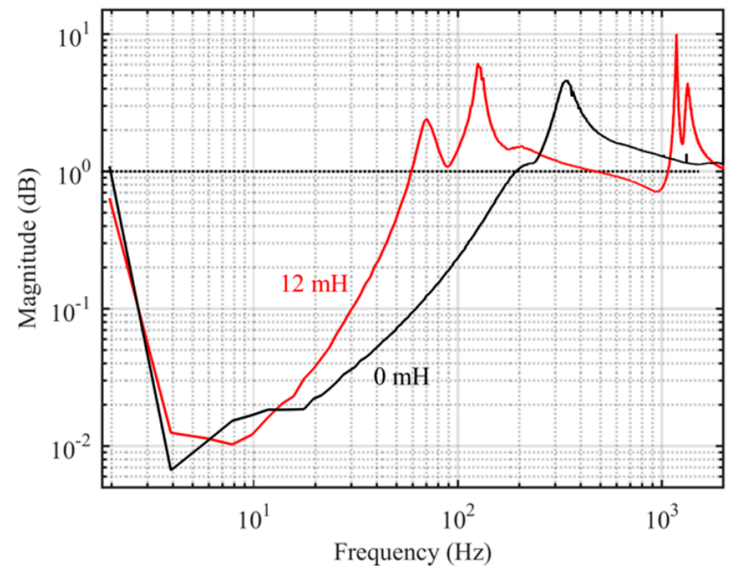

Figure 31. The maximum singular values of $\mathbf{S}_{\mathrm{c}}=\left[\mathbf{I}+\mathbf{L}_{\mathbf{c}}\right]^{-1}$ at $L_{2}=0$ (black line) and $L_{2}=12 \mathrm{mH}$.

The measured inductor-current-loop d and q components in Figure 28, the Nyquist plot of $\operatorname{det}[\mathbf{I}+$ $\left.\mathbf{L}_{\mathbf{C}}\right]$ in Figure 30, and the maximum singular values in Figure 31 imply that the stability of the converter is not robust and the converter may be very close to instability. Figure 32 shows the response of the 
inductor-current q component to a 5-A step change in its reference. The response indicates decaying oscillation approximately at $90 \mathrm{~Hz}$, which equals the crossover frequency of the inductor-current-loop $\mathrm{q}$ component with the phase margin of 20 degrees. The response indicate definitively that the converter is stable similarly as the Nyquist plot of $\operatorname{det}\left[\mathbf{I}+\mathbf{Y}_{\text {inv-o }} \mathbf{X}_{\text {grid }}\right]$ in Figure $26 \mathbf{b}$.
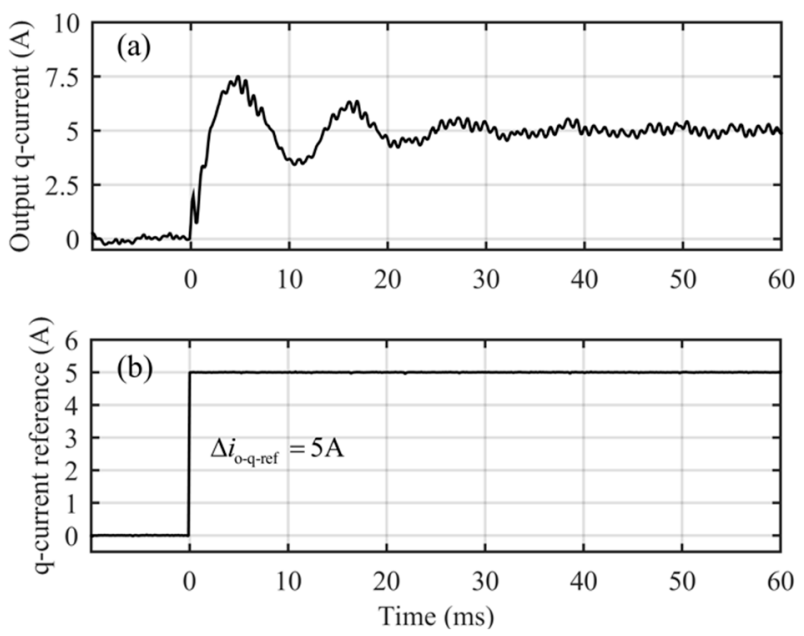

Figure 32. Response of inductor-current q component (a) to a 5A step change in its reference (b).

\subsubsection{Discussions}

The stability of the grid-feeding-mode inverter was assessed by means the measured output- terminal-side multivariable impedance ratio and the measured inductor-current-loop gains, when the weak-grid condition was emulated by adding a 12-mH series inductor in the grid side. The time-domain operation of the inverter implied stable operation. The Nyquist plots of $\operatorname{det}\left[\mathbf{I}+\mathbf{Y}_{\text {inv-o }} \mathbf{X}_{\text {grid }}\right]$ (cf. Figure 26b) and $\operatorname{det}\left[\mathbf{I}+\mathbf{L}_{C}\right]$ (cf. Figure 29) indicate explicitly that the inverter is stable but the stability margins are poor, which the time-domain step response of the inductor-current q component also confirmed explicitly (cf. Figure 32). The eigenvalue plots implied that the inverter is unstable. The impedance-ratio-based maximum-singular-value plot shows explicitly that the stability is not robust at the low frequencies (up $60 \mathrm{~Hz}$ ) and at the high frequencies $(>1 \mathrm{kHz})$. It was also shown that the obtainable stability information is very poor when the cross-couplings are neglected.

As discussed in Reference [89], the multivariable impedance measurements are extremely difficult to be performed due to the grid-impedance effect on the synchronization [90] as well as the highly varying nature of the grid impedance [91,92], and therefore, the accuracy of the measurements may be questionable. The same applies also to the measurements of the feedback-loop gains. The observed variance in the information provided by the different stability-assessment methods may be the consequence of the inaccurate measurement results as well.

\section{Conclusions}

The dynamic behavior and the factors affecting the sensitivity of the power electronic converters to the external impedance interactions are fully solved for the DC-DC converters as described in Reference ([12], Parts 2 and 3). The dynamic analysis of the three-phase power electronics converters is still in its infancy. The reason for this is obviously the high complexity of the elements affecting their dynamic behavior. The usual method to relax the complexity is to remove the cross-coupling terms of the associated multivariable transfer functions, which deteriorates also the obtainable stability information.

This paper has shown that the three-phase grid-tied converters have similar internal impedance-like parameters as the DC-DC converters have, which affect the converter sensitivity to the source and load-impedance-induced interactions. The source and load interactions of the three-phase grid-tied converter can be solved with ease by using proper software packages such as Matlab ${ }^{\mathrm{TM}}$. 
This paper provides the explicit formulations for the implicit internal parameters, which governs the interactions through the DC interface. The full-order formulations for the three-phase interface cannot be obtained, because the relevant source/load-affected transfer functions cannot be put into the form stipulated by the EET method. It is obvious that further studies are needed for analyzing the interactions and their relations to the implicit internal parameters.

Intensive research on the impedance-based stability analysis has been going on for several years already. The complexity of the analyses has led to simplifying the impedance-based minor-loop gains by omitting the cross-couplings between the different impedances constituting the minor-loop gain. The experimental measurements, in this paper, show clearly that the omitting of the cross-couplings will easily lead to inaccurate information on the robustness and state of the stability. We have shown, in this paper, that the stability assessment based on $\operatorname{det}\left[\mathbf{I}+\mathbf{Y}_{\text {inv-o }} \mathbf{X}_{\text {grid }}\right]$ may give the most accurate information on the state of stability, which was confirmed by assessing the stability by means of $\operatorname{det}\left[\mathbf{I}+\mathbf{L}_{\mathbf{C}}\right]$ (i.e., the measured inductor-current feedback loop).

The content of the paper is intended to initialize extensive studies in the dynamic behavior of the three-phase grid-tied converters as well as in the measurement methods of dq-domain frequency responses to improve their accuracy.

Author Contributions: T.S. wrote the paper, T.M. has been responsible for the basic theories related to the inverters, M.B., H.A., T.R., and R.L. performed the practical measurements and provided the measurement data, K.Z. has been responsible for the theories related to the multivariable stability assessment.

Funding: This research received no external funding.

Conflicts of Interest: The authors declare no conflicts of interest.

\section{References}

1. Yuan, Y.; Biess, J.J. Some design aspects concerning input filters for DC-DC converters. In Proceedings of the IEEE Power Electronics Specialist Conference (IEEE PESC), Pasadena, CA, USA, 19-20 April 1971; pp. 66-76.

2. Sokal, N.O. System oscillations from negative input resistance at the power input of port switching regulator, amplifier, DC/DC converter, or DC/AC inverter. In Proceedings of the IEEE Power Electronics Specialist Conference (IEEE PESC), Pasadena, CA, USA, 11-13 June 1973; pp. 138-140.

3. Wester, G.W.; Middlebrook, R.D. Low-frequency characterization of switched dc-dc converters. IEEE Trans. Aerosp. Electron. Syst. 1973, AES-9, 376-385. [CrossRef]

4. Middlebrook, R.D.; Ćuk, S. A general unified approach to modelling switching-converter power stages. In Proceedings of the IEEE Power Electronics Specialist Conference (IEEE PESC), Cleveland, OH, USA, 8-10 June 1976; pp. 18-34.

5. Middlebrook, R.D.; Ćuk, S. A general unified approach to modelling switching-converter power stages. Int. J. Electron. 1977, 42, 521-550. [CrossRef]

6. Middlebrook, R.D. Input filter considerations in design and application of switching regulators. In Proceedings of the Industry Application Society Annual Meeting (IEEE IAS), Chicago, IL, USA, 1-14 October 1976; pp. 91-107.

7. Middlebrook, R.D. Design techniques for preventing input-filter oscillations in switched-mode regulators. In Proceedings of the The 5th National Solid-State Power Conversion Conference (Powercon 5), San Francisco, CA, USA, 4-6 May 1978; pp. A3.1-A3.16.

8. Middlebrook, R.D. The two extra element theorem. In Proceedings of the Frontiers in Education Conference, West Lafayette, IN, USA, 21-24 September 1991; pp. 702-708.

9. Middlebrook, R.D. Null double injection and the extra element theorem. IEEE Trans. Educ. 1989, 32, 167-180. [CrossRef]

10. Vesti, S.; Suntio, T.; Oliver, J.A.; Prieto, R.; Cobos, J.A. Impedance-based stability and transient-performance assessment applying maximum peak criteria. IEEE Trans. Power Electron. 2013, 28, 2099-2104. [CrossRef]

11. Vesti, S.; Suntio, T.; Oliver, J.A.; Prieto, R.; Cobos, J.A. Effect of control method on impedance-based interactions in a buck converter. IEEE Trans. Power Electron. 2013, 28, 5311-5322. [CrossRef] 
12. Suntio, T.; Messo, T.; Puukko, J. Power Electronics Converters-Dynamics and Control in Conventional and Renewable Energy Applications; Wiley-VCH: Weinheim, Germany, 2018.

13. Nyquist, H. Regeneration theory. Bell. Syst. Tech. J. 1932, 11, 126-147. [CrossRef]

14. Skogestad, S.; Postlethwaite, I. Multivariable Feedback Control; Wiley: Chichester, UK, 1996.

15. Maciejowski, J.M. Multivariable Feedback Design; Addison-Wesley: Wokingham, UK, 1989.

16. Wildrick, C.M.; Lee, F.C.; Cho, B.H.; Choi, B. A method of defining the load impedance specifications for a stable distributed power system. IEEE Trans. Power Electron. 1995, 10, 280-285. [CrossRef]

17. Sudhoff, S.D.; Glover, S.F.; Lamm, P.T.; Schmucker, D.H.; Delisle, D.E. Admittance space stability analysis of power electronic system. IEEE Trans. Aerosp. Electron. Syst. 2000, 36, 965-973. [CrossRef]

18. Feng, X.; Liu, J.; Lee, F.C. Impedance specifications for stable dc distributed power system. IEEE Trans. Power Electron. 2002, 17, 157-162. [CrossRef]

19. Riccobono, A.; Santi, E. Comprehensive review of stability criteria for DC power distribution systems. IEEE Trans. Ind. Appl. 2014, 50, 3525-3535. [CrossRef]

20. Wen, B.; Burgos, R.; Boroyevich, D.; Mattavelli, P.; Shen, Z. AC stability analysis and dq frame impedance specifications in power-electronics-based distributed power systems. IEEE J. Emerg. Sel. Top. Power Electron. 2017, 5, 1455-1465. [CrossRef]

21. Harnefors, L. Modeling of three-phase dynamic systems using complex transfer functions and transfer matrices. IEEE Ind. Electron. 2007, 54, 2239-2248. [CrossRef]

22. Messo, T.; Aapro, A.; Suntio, T. Generalized multivariable small-signal model of three-phase grid-connected inverter in DQ domain. In Proceedings of the IEEE 16th Workshop Control. Model. Power Electron. (COMPEL), Vancouver, BC, Canada, 12-15 June 2015; pp. 1-8.

23. Wang, Z.; Harnefors, L.; Blaabjerg, F. Unified impedance model of grid-connected voltage-source converters. IEEE Trans. Power Electron. 2018, 33, 1775-1787. [CrossRef]

24. Lu, D.; Wang, Z.; Blaabjerg, F. Impedance-based analysis of DC-link voltage dynamics in voltage-source converters. IEEE Trans. Power Electron. 2018, in press. [CrossRef]

25. Aapro, A.; Messo, T.; Suntio, T. An accurate small-signal model of a three-phase VSI-based photovoltaic inverter with LCL filter to predict inverter output impedance. In Proceedings of the International Conference Power Electron. (ICPE ECCE Asia), Seoul, Korea, 1-5 June 2015; pp. 2267-2274.

26. Berg, M.; Messo, T.; Suntio, T. Frequency response analysis of load effect on dynamics of grid-forming inverter. In Proceedings of the Int. Power Elect. Conference (IPEC-Niigata ECCE Asia), Niigata, Japan, 20-24 May 2018; pp. 963-970.

27. MacFarlane, A.G.J.; Postlethwaite, I. The generalized Nyquist stability criterion. Int. J. Control 1977, 25, 81-127. [CrossRef]

28. Desoer, C.A.; Wang, Y.-T. On the generalized Nyquist stability criterion. IEEE Trans. Autom. Control 1980, 25, 187-196. [CrossRef]

29. Harnefors, L.; Buongiorno, M.; Lundberg, S. Input-admittance calculation and shaping for controlled voltage-source converters. IEEE Trans. Ind. Electron. 2007, 54, 3323-3334. [CrossRef]

30. Puukko, J.; Messo, T.; Suntio, T. Negative output impedance in three-phase grid-connected renewable energy source inverters based on reduced-order models. In Proceedings of the IET Conference on Renewable Power Generation (RPG 2011), Edinburg, UK, 6-8 September 2011; pp. 1-6.

31. Harnefors, L.; Yepes, A.G.; Vidal, A.; Doval-Gandoy, J. Passivity-based controller design of grid-connected VSCs for prevention of electrical resonance instability. IEEE Trans. Ind. Electron. 2015, 62, 702-710. [CrossRef]

32. Zhang, C.; Cai, X.; Li, Z.; Rygg, A.; Molinas, M. Properties and physical interpretations of the dynamic interactions between voltage source converters and grid: Electrical oscillation and its stability control. IET Power Electron. 2017, 10, 894-902. [CrossRef]

33. Nousiainen, L.; Suntio, T. Simple VSI-based single-phase inverter: Dynamical effect of photovoltaic generator and multiplier-based grid synchronization. In Proceedings of the IET Conference on Renewable Power Generation (RPG 2011), Edinburg, UK, 6-8 September 2011; pp. 1-6.

34. Khazaei, J.; Miao, Z.; Piyasinghe, L. Impedance-model-based MIMO analysis of power synchronization control. Electr. Power Syst. Res. 2018, 154, 341-351. [CrossRef]

35. Cho, Y.; Hur, K.; Kang, Y.C.; Muljadi, E. Impedance-based stability analysis in grid interconnection impact study owing to the increased adoption of converter-interfaced generators. Energies 2017, 10, 1355. [CrossRef] 
36. Krismanto, A.U.; Mithulananthan, N.; Krause, O. Stability of renewable energy based microgrid in autonomous operation, Sustainable. Energy Grids Netw. 2018, 13, 134-147.

37. Krismanto, A.U.; Mithulananthan, N.; Kamwa, I. Oscillatory stability assessment of microgrid in autonomous operation with uncertainties. IET Renew. Power Gener. 2016, 31, 494-504. [CrossRef]

38. Krismanto, A.U.; Mithulananthan, N. Identification of modal interaction and small signal stability in autonomous microgrid operation. IET Gener. Transm. Distrib. 2018, 12, 247-257. [CrossRef]

39. Liu, H.; Sun, J. Voltage stability and control of offshore wind farms with AC collection and HVDC transmission. IEEE J. Emerg. Sel. Top. Power Electron. 2014, 2, 1181-1189.

40. Amin, M.; Molinas, M. Understanding the origin of oscillatory phenomena observed between wind farms and HVDC systems. IEEE J. Emerg. Sel. Top. Power Electron. 2017, 5, 378-392. [CrossRef]

41. Liu, Z.; Su, M.; Sun, Y.; Han, H.; Hou, X.; Guerrero, J.M. Stability analysis of DC microgrids with constant power load under distributed control methods. Automatica 2018, 90, 62-72. [CrossRef]

42. AL-Nussairi, M.; Bayindir, R.; Padmanaban, S.; Mohet-Popa, L.; Siano, P. Constant power loads (CPL) with microgrids: Problem definition, stability analysis and compensation techniques. Energies 2017, 10, 1656. [CrossRef]

43. Du, W.; Jiang, G.; Erickson, M.; Lasseter, R.H. Voltage-source control of PV inverter in a CERTS microgrid. IEEE Trans. Power Deliv. 2014, 29, 1726-1734. [CrossRef]

44. Cespedes, M.; Sun, J. Adaptive control of grid-connected inverters based on online grid impedance measurement. IEEE Trans. Sustain. Energy 2014, 5, 516-523. [CrossRef]

45. Krishnayya, P.C.S.; Piwko, R.J.; Weaver, T.L.; Bahrman, M.P.; Hammad, A.E. DC-transmission terminating at low short circuit ratio locations. IEEE Trans. Power Deliv. 1986, 1, 308-318. [CrossRef]

46. Diedrichs, V.; Beekmann, A.; Busker, K.; Nikolai, S.; Adloff, S. Control of wind power plants utilizing voltage source converter in high-impedance grids. In Proceedings of the 2012 IEEE Power and Energy Society General Meeting, San Diego, CA, USA, 22-26 July 2012; pp. 1-8.

47. Zhou, J.Z.; Ding, H.; Fan, S.; Zhang, Y.; Gole, A.M. Impact of short-circuit ratio and phase-locked-loop parameters on the small-signal behavior of a VSC-HVDC converter. IEEE Trans. Power Deliv. 2014, 29, 2287-2296. [CrossRef]

48. Etxegarai, P.; Egui, P.; Torres, E.; Iturregi, A.; Valverde, V. Review of grid connection requirements for generation assets in weak power grids. Renew. Sustain. Energy Rev. 2015, 41, 1501-1514. [CrossRef]

49. Schwanka Trevisan, A.; Mendonca, A.; Fisher, M.; Adloff, S.; Nikolai, S.; El-Deib, A. Process and tools for optimizing wind power projects connected to weak grids. IET Renew. Power Gener. 2018, 12, 539-546. [CrossRef]

50. Krishayya, P.C.; Adapa, R.; Holm, M. IEEE Guide for Planning DC Links Terminating at AC Locations Having Low Short-Circuit Capacities; IEEE Std 1204-1997 (R2003); IEEE: Piscataway, NJ, USA, 1997.

51. Wen, B.; Dong, D.; Boroyevich, D.; Burgos, R.; Mattavelli, P.; Shen, Z. Impedance-based analysis of grid-synchronization stability for three-phase parallel converters. IEEE Trans. Power Electron. 2016, 31, $26-38$. [CrossRef]

52. Amin, M.; Rygg, A.; Molinas, M. Self-synchronization of wind farm in an MMC-based HVDC system: A stability investigation. IEEE Trans. Energy Convers. 2017, 32, 458-470. [CrossRef]

53. Suul, J.A.; D'Arco, S.; Rodriquez, P.; Molinas, M. Impedance-compensated grid synchronisation for extending the stability range of weak grids with voltage source converters. IET Gener. Transm. Distrib. 2016, 10, 1315-1326. [CrossRef]

54. Li, X.; Lin, H. Stability analysis of grid-connected converters with different implementations of adaptive PR controllers under weak grid conditions. Energies 2018, 11, 2004. [CrossRef]

55. Blanchard, J. History of electrical resonance. Bell Syst. Tech. J. 1941, 20, 415-433. [CrossRef]

56. Agbemuko, A.J.; Dominguez-Garcia, J.L.; Prieto-Araujo, E.; Gomis-Bellmunt, O. Impedance modelling and parametric sensitivity of a VSC-HVDC system: New insights on resonances and interactions. Energies 2018, 11, 845. [CrossRef]

57. Enslin, J.H.R.; Heskes, P.J.M. Harmonic interaction between a large number of distributed power inverters and the distribution network. IEEE Trans. Power Electron. 2004, 19, 1586-1593. [CrossRef]

58. Wang, X.; Blaabjerg, F.; Wu, W. Modeling and analysis of harmonic stability in an AC power-electronics-based power system. IEEE Trans. Power Electron. 2014, 29, 6421-6432. [CrossRef] 
59. Pereira, H.A.; Freijedo, F.D.; Silva, M.M.; Mendes, V.F.; Teodorescu, R. Harmonic current prediction by impedance modeling of grid-tied inverters: A 1.4 MW PV plant case study. Electr. Power Energy Syst. 2017, 93, 30-38. [CrossRef]

60. Du, Y.; Lu, D.D.-C.; James, G.; Cornforth, D. Modeling and analysis of current harmonic distortion from grid connected PV inverters under different operating conditions. Sol. Energy 2017, 94, 182-194. [CrossRef]

61. Chicco, G.; Schlabbach, J.; Spertino, F. Experimental assessment of the waveform distortion in grid-connected photovoltaic installations. Sol. Energy 2009, 83, 1026-1039. [CrossRef]

62. Pakonen, P.; Hilden, A.; Suntio, T.; Verho, P. Grid-connected PV-power-plant-induced power quality problems-Experimental evidence. In Proceedings of the 2016 18th European Conference on Power Electronics and Applications (EPE'16 ECCE Europe), Karlsruhe, Germany, 5-9 September 2016; pp. 1-10.

63. Li, C. Unstable operation of photovoltaic inverter from filed experiences. Power Eng. Lett. 2018, 33, $1013-1015$.

64. Rocabert, J.; Luna, A.; Blaabjerg, F.; Rodriguez, P. Control of power converters in AC microgrids. IEEE Trans. Power Electron. 2012, 27, 4734-4749. [CrossRef]

65. Viinamäki, J.; Suntio, T.; Kuperman, A. Grid-forming-mode operation of boost-power-stage converter in PV-interfacing applications. Energies 2017, 10, 1033. [CrossRef]

66. Wang, J.; Chang, N.; Feng, X.; Monti, A. Design of a generalized algorithm for parallel inverters for smooth microgrid transition operation. IEEE Trans. Ind. Electron. 2015, 62, 4900-4914. [CrossRef]

67. Blaabjerg, F.; Teodorescu, R.; Liserre, M.; Timbus, A.V. Overview of control and grid synchronization for distributed power generation. IEEE Trans. Ind. Electron. 2006, 53, 1398-1409. [CrossRef]

68. Kolesnik, S.; Sitbon, M.; Agranovich, G.; Kuperman, A.; Suntio, T. Comparison of photovoltaic and wind generators as dynamic input sources to power processing interfaces. In Proceedings of the 2nd International Conference Intelligent Energy \& Power Syst. (IEPS), Kiev, Ukraine, 7-11 June 2016; pp. 1-5.

69. Kolesnik, S.; Kuperman, A. On the similarity between low-frequency equivalent circuits of photovoltaic and wind generators. IEEE Trans. Energy Convers. 2015, 30, 407-409. [CrossRef]

70. Kolesnik, S.; Kuperman, A. Analytical derivation of electric-side maximum power line for wind generators. Energies 2017, 10, 10. [CrossRef]

71. Kolesnik, S.; Sitbon, M.; Batzelis, E.; Suntio, T.; Kuperman, A. Solar irradiation independent expression for photovoltaic generator maximum power line. IEEE J. Photovolt. 2017, 7, 1416-1420. [CrossRef]

72. Xia, Y.; Ahmed, K.H.; Williams, B. Wind turbine power coefficient analysis of a new maximum power point tracking technique. IEEE Trans. Ind. Electron. 2013, 60, 1122-1132. [CrossRef]

73. Suntio, T.; Leppäaho, J.; Huusari, J.; Nousiainen, L. Issues on solar-generator interfacing with current-fed MPP-tracking converters. IEEE Trans. Power Electron. 2010, 25, 2409-2419. [CrossRef]

74. Mäki, A.; Valkealahti, S.; Suntio, T. Dynamic Terminal Characteristics of a Solar Generator, it7680. Available online: https://www.google.com.tw/url?sa=t\&rct=j\&q=\&esrc=s\&source=web\&cd=1\&ved= 2ahUKEwiLmfHHm5XgAhVb7mEKHYNzAtwQFjAAegQIBBAB\&url=https\%3A\%2F\%2Fieeexplore.ieee. org\%2Fdocument\%2F5606786\%2F\&usg=AOvVaw3fqyKWELX8TcRTwHvS4mp3 (accessed on 25 May 2018).

75. Mäki, A.; Valkealahti, S. Effect of photovoltaic generator components on the number of MPPs under partial shading conditions. IEEE Trans. Energy Convers. 2013, 28, 1008-1017. [CrossRef]

76. Wyatt, J.; Chua, L. Nonlinear resistive maximum power theorem with solar cell application. IEEE Trans. Circuits Syst. 1983, 30, 824-828. [CrossRef]

77. Suntio, T. Dynamic Profile of Switched-Mode Converter-Modeling, Analysis and Control; Wiley-VCH: Weinheim, Germany, 2009.

78. Bakhshzadeh, M.K.; Wang, Z.; Blaabjerg, F.; Hjerrild, J.; Kocewiak, L.; Leth Bak, K.; Hesselbaek, B. Couplings in phase domain impedance modeling of grid-connected converters. IEEE Trans. Power Electron. 2016, 31, 6792-6796.

79. Liu, Z.; Liu, J.; Bao, W.; Zhao, Y. Infinity-norm of impedance-based stability criterion for three-phase AC distribution power systems with constant power loads. IEEE Trans. Power Electron. 2015, 30, 3030-3043. [CrossRef]

80. Roinila, T.; Messo, T.; Santi, E. MIMO-identification techniques for rapid impedance based stability assessment of three-phase systems in dq-domain. IEEE Trans. Power Electron. 2018, 33, 4015-4022. [CrossRef]

81. Wen, B.; Boroyevich, D.; Burgos, R.; Mattavelli, P.; Shen, Z. Small-signal stability analysis of three-phase AC systems in the presence of constant power loads based on measured d-q frame impedances. IEEE Trans. Power Electron. 2015, 30, 5952-5963. [CrossRef] 
82. Wen, B.; Boroyevich, D.; Burgos, R.; Mattavelli, P.; Shen, Z. Analysis of d-q small-signal impedance of grid-tied inverters. IEEE Trans. Power Electron. 2016, 31, 675-687. [CrossRef]

83. Sun, J. Impedance-based stability criterion for grid-connected inverters. IEEE Trans. Power Electron. 2011, 26, 3075-3078. [CrossRef]

84. Wen, B.; Boroyevich, D.; Burgos, R.; Mattavelli, P.; Shen, Z. Inverse Nyquist stability criterion for grid-tied inverters. IEEE Trans. Power Electron. 2017, 32, 1548-1556. [CrossRef]

85. Dong, D.; Wen, B.; Boroyevich, D.; Mattavelli, P.; Xue, Y. Analysis of phase-locked loop low-frequency stability in three-phase grid-connected power converters. IEEE Trans. Ind. Electron. 2015, 62, 310-321. [CrossRef]

86. Tse, C.K. Linear Circuit Analysis; Addison-Wesley Longman: Harlow, UK, 1998.

87. Aapro, A.; Messo, T.; Suntio, T.; Roinila, T. Effect of active damping on output impedance of three-phase grid-connected converter. IEEE Trans. Ind. Electron. 2017, 64, 7532-7541. [CrossRef]

88. Francis, G.; Burgos, R.; Boroyevich, D.; Waqng, F.; Karimini, K. An algorithm and implementation system for measuring impedance in the D-Q domain. In Proceedings of the IEEE Energy Convers. Cong. \& Expo, Phoenix, AZ, USA, 17-22 September 2011; pp. 3221-3228.

89. Liao, Y.; Wang, X. General rules of using bode plots for impedance-based stability analysis. In Proceedings of the IEEE 19th Workshop Control. Model. Power Electron. (COMPEL), Padua, Italy, 25-28 June 2018; pp. 1-6.

90. Gong, H.; Yang, D.; Wang, X. Impact of synchronization phase dynamics on dq impedance measurement. In Proceedings of the IEEE 19th Workshop Control. Model. Power Electron (COMPEL), Padova, Italy, 25-28 June 2018; pp. 1-5.

91. Jessen, L.; Fuchs, F.W. Modeling of inverter output impedance for stability analysis in combination with measured grid impedance. In Proceedings of the IEEE 16th Workshop Control. Model. Power Electron. (COMPEL), Vancouver, BC, Canada, 12-15 June 2015; pp. 1-7.

92. Jessen, L.; Gunter, S.; Fuchs, F.W.; Gottschalk, M.; Hinrichs, H.-J. Measurement result and performance analysis of the grid impedance in different low voltage grids for wide frequency band to support grid integration of renewables. In Proceedings of the IEEE Energy Conversion Cong. \& Expo (IEEE ECCE), Montreal, QC, Canada, 20-24 September 2015; pp. 1960-1967. 